\title{
Regulation of Neurotransmitter Vesicles by the Homeodomain Protein UNC-4 and Its Transcriptional Corepressor UNC-37/Groucho in Caenorhabditis elegans Cholinergic Motor Neurons
}

\author{
Kim M. Lickteig, ${ }^{1}$ Janet S. Duerr, ${ }^{2}$ Dennis L. Frisby, ${ }^{2}$ David H. Hall, ${ }^{3}$ James B. Rand, ${ }^{2}$ and David M. Miller III ${ }^{1}$ \\ ${ }^{1}$ Department of Cell Biology, Vanderbilt University Medical Center, Nashville, Tennessee 37232, 2Program in Molecular \\ and Cell Biology, Oklahoma Medical Research Foundation, Oklahoma City, Oklahoma 73104, and ${ }^{3}$ Center for C. elegans \\ Anatomy, Albert Einstein College of Medicine, Bronx, New York 10461
}

\begin{abstract}
Motor neuron function depends on neurotransmitter release from synaptic vesicles (SVs). Here we show that the UNC-4 homeoprotein and its transcriptional corepressor protein UNC-37 regulate SV protein levels in specific Caenorhabditis elegans motor neurons. UNC-4 is expressed in four classes (DA, VA, VC, and SAB) of cholinergic motor neurons. Antibody staining reveals that five different vesicular proteins (UNC-17, choline acetyltransferase, Synaptotagmin, Synaptobrevin, and RAB-3) are substantially reduced in unc -4 and unc- 37 mutants in these cells; nonvesicular neuronal proteins (Syntaxin, UNC18, and UNC-11) are not affected, however. Ultrastructural analysis of VA motor neurons in the mutant unc-4(e120) confirms that SV number in the presynaptic zone is reduced ( $40 \%)$ whereas axonal diameter and synaptic morphology are not visibly altered. Because the UNC-4-UNC-37 complex has been shown to mediate transcriptional repression, we propose
\end{abstract}

that these effects are performed via an intermediate gene. Our results are consistent with a model in which this unc- 4 target gene ("gene- $x$ ") functions at a post-transcriptional level as a negative regulator of SV biogenesis or stability. Experiments with a temperature-sensitive unc-4 mutant show that the adult level of SV proteins strictly depends on unc-4 function during a critical period of motor neuron differentiation. unc-4 activity during this sensitive larval stage is also required for the creation of proper synaptic inputs to VA motor neurons. The temporal correlation of these events may mean that a common unc-4dependent mechanism controls both the specificity of synaptic inputs as well as the strength of synaptic outputs for these motor neurons.

Key words: synaptic vesicles; cholinergic differentiation; C. elegans; synaptic specificity; neural development; unc-4
The function of motor neuron circuits depends on synaptic transmission between specific cells. Studies of the nematode Caenorhabditis elegans have revealed that a homeodomain protein encoded by the unc-4 gene controls the pattern of synaptic inputs to one class of motor neurons in the ventral nerve cord (Miller et al., 1992; White et al., 1992). The strong backward movement defect that unc-4 mutants display is correlated with the miswiring of VA motor neurons with synapses from command interneurons normally reserved for their lineal sister cells, the VB motor neurons. Expression of the UNC-4 protein in the VA motor neurons rescues this phenotype and thereby establishes that $u n c-4$ functions in the postsynaptic cell (i.e., VA motor neuron) to block input from inappropriate presynaptic partners (i.e., VB-type command interneurons) (Miller and Niemeyer, 1995). UNC-4 activity requires physical interaction with UNC-37, a ubiquitously

\footnotetext{
Received June 20, 2000; revised Oct. 16, 2000; accepted Nov. 28, 2000.

This work was supported by National Institutes of Health Grants MH12260 (K.M.L.), NS26115 (D.M.M.), GM38679 (J.B.R.), and NCRR12596 (D.H.H.) and OCAST Grant HN3-023 (J.S.D.). We thank R. Blakely and members of the D. M. Miller and D. Greenstein laboratories for helpful discussions; M. Nonet for antibodies against RAB-3, Synaptobrevin, and Syntaxin and for the unc-4 promoterSNB-1::GFP plasmid; A. Alfonso for the unc-11(n2954) strain and UNC-11 antibody; John White for wild-type and unc-4(e120) electron micrographs; Tylon Stephney for scanning EM prints; and Chris Li for communicating unpublished data. Correspondence should be addressed to Dr. David M. Miller, III, C2310 Medical Center North, 1161 21st Avenue South, Vanderbilt University, Nashville, TN 37232. E-mail: david.miller@mcmail.vanderbilt.edu.

Copyright (C) 2001 Society for Neuroscience 0270-6474/01/212001-14\$15.00/0
}

expressed Groucho-like transcriptional corepressor protein (Miller et al., 1993; Pflugrad et al., 1997). Thus, we have proposed that the creation of appropriate synaptic inputs to VA motor neurons depends on UNC-4-UNC-37-mediated repression of "VBspecific genes" (Winnier et al., 1999).

$\mathrm{LacZ}$ and green fluorescent protein (GFP) reporter genes have also detected unc-4 expression in additional classes of motor neurons in the ventral nerve cord and in flanking ganglia (Miller and Niemeyer, 1995; Pflugrad et al., 1997). Because these motor neurons (e.g., DAs) are not miswired with improper inputs in unc-4 mutants (White et al., 1992), the functional significance of unc-4 expression in these cells has been unclear. Here we show that unc-4 and unc-37 mutations result in decreased levels of synaptic vesicle (SV) proteins in all unc-4-expressing motor neurons and that this deficit impairs the function of these cells.

SVs are clustered near the presynaptic density (PSD) where they are poised for rapid membrane fusion and release of neurotransmitter (for review, see Calakos and Scheller, 1996). Specialized vesicular proteins are incorporated into the SVs to modulate these events. Vesicle exocytosis and recycling also depend on interactions with cytoplasmic and axonal membrane proteins. Expression of these synaptic proteins is developmentally regulated and subject to both transcriptional and post-transcriptional mechanisms of control (Bergmann et al., 1991; Lou and Bixby, 1993; Melloni et al., 1994; Petersohn et al., 1995; Deans et al., 1997; Smith et al., 1997). Additional homeostatic mechanisms of 
regulation are suggested by the observation that neurons in many systems contain different types and numbers of synaptic vesicles (White et al., 1986; Jia et al., 1993; Merchan-Perez and Liberman, 1996; Jin et al., 1999). These differences may indicate that SV levels are actively regulated in each of these cell types to satisfy specific physiological requirements.

The evolutionary conservation of the secretory apparatus has facilitated the use of genetic approaches in simple model systems to discover new components of the mammalian exocytic pathway and to define their modes of action (Rothman, 1994; M. Nonet, 1999; Lloyd et al., 2000). Because UNC-4 and its cofactor UNC-37 (Pflugrad et al., 1997) have been shown to function as transcriptional repressors (Winnier et al., 1999), the decreased levels of vesicular proteins that we observe in $u n c-4$ and $u n c-37$ mutants must result from an indirect mechanism of action; UNC-4 and UNC-37 may repress a target gene ("gene-x") that in turn exerts a negative effect on vesicular protein levels. Furthermore, our results indicate that this presumptive downstream gene acts via a post-transcriptional mechanism; derepression of gene- $x$ in $u n c-4$ or $u n c-37$ mutants must either constrain SV biogenesis or enhance SV turnover. These outcomes are strictly dependent on unc-4 activity during embryonic and early larval stages of motor neuron differentiation; SV protein expression does not require unc-4 function in the adult. This finding parallels a previous observation that the specificity of synaptic inputs to one class of cholinergic motor neurons (e.g., VAs) also depends on unc-4 function during a concurrent period of larval growth (Miller et al., 1992). The temporal coincidence of these events offers the intriguing possibility that both the specificity of synaptic inputs as well as the strength of synaptic outputs for these motor neurons may depend on a common unc-4-regulated mechanism.

\section{MATERIALS AND METHODS}

Nematode strains. C. elegans were grown as described (Brenner, 1974). The N2 (Bristol) strain was used as the wild-type strain. All genetic experiments were performed at $25^{\circ} \mathrm{C}$ with the exception that the unc4(e2322ts) strain (Miller et al., 1992) was grown at the permissive temperature of $16^{\circ} \mathrm{C}$ when noted.

Chromosomal integration of the $u n c-4$ promoter-gfp line (wdIs5) was achieved by $\gamma$ irradiation (4000 rads). Animals with $g f p$ reporter genes [wdIs5, unc-17-cha-1p::gfp, and unc-4p::synaptobrevin-1 (SNB-1)::gfp] were anesthetized with $1 \%$ tricaine and tetramisole and assessed as described previously (Miller et al., 1999). The following mutant strains were used: in linkage group I (LG I), unc-37(e262), unc-37(wd17), bli4(e937), unc-11(n2954), and unc-13(e51); in LG II, bli-2(e768), unc104(e1265), unc-4 alleles e120,wd1, e26, e2321, and e2322ts; and in LG IV, dpy-20(e1282), unc-17(e113), and cha-1(md39ts).

Genetics. unc-4 unc-104 double mutants were constructed by first marking unc-4 with bli-2. unc-104 was crossed into the bli-2 unc-4 strains, and nonblister Unc-4 animals were picked to select for a crossover event between bli-2 and unc-104. The presence of unc-4 in the unc-4 unc-104 double mutant was verified by a complementation test using unc4(e2322ts) males (Miller et al., 1993).

unc-37(wd17)-containing strains were constructed by crossing bli-4 unc-37(wd17) animals (Miller et al., 1993) with unc-4 unc-104 strains. The presence of the $w d 17$ mutation in this strain was confirmed by the appearance of non-Unc-4 progeny from matings with unc-4(e2322ts) males at the restrictive temperature $\left(25^{\circ} \mathrm{C}\right)$.

UNC-18 antibody. The DNA sequence corresponding to amino acids 18-584 of UNC-18 was amplified from a cDNA library by PCR and cloned into pRSETB (Invitrogen, San Diego, CA). A fusion protein with a $6 \times$-His terminal tag was expressed with the Xpress System (Invitrogen) and purified over a ProBond resin column. Purified fusion protein was used to immunize two goats and two rabbits. Anti-UNC-18 was affinity purified with the fusion protein coupled with methanol to nitrocellulose filters (Duerr et al., 1999). Antiserum from one goat (G247) gave the most specific signal on fixed $C$. elegans and was used for this study.

Synaptotagmin antibody. A bacterially expressed fusion protein con- taining amino acids 144-441 of the synaptotagmin (SNT-1) protein was produced and purified as described previously (Nonet et al., 1993) and used to immunize rabbits. The resulting sera were affinity purified using the bacterial fusion protein.

Immunofluorescence. To evaluate antibody staining of the DA and VA motor neurons, animals were synchronized using a Chlorox and $\mathrm{NaOH}$ solution, and the resultant embryos were grown to the late L2 stage (Sulston and Hodgkin, 1988). Antibody staining of the DAs and VAs was performed within $1 \mathrm{~d}$ of fixation to preserve the GFP fluorescence that tended to fade with time. Adult animals were antibody-stained for evaluation of vesicular and neuronal protein expression in the $\mathrm{VC}$ and SAB motor neurons. All antibodies were diluted in antibody buffer B, pH 7.2 (1× PBS, 0.5\% Triton X-100, 1 mm EDTA, pH 8.0, and 0.1\% BSA) (Duerr et al., 1999). Stained animals were placed in a mounting media containing $200 \mathrm{mg} / \mathrm{ml} n$-propyl gallate, $30 \mathrm{~mm}$ Tris, pH 9, 70\% glycerol, and $20 \mu \mathrm{g} / \mathrm{ml} \mathrm{4}^{\prime}$,6-diamidino-2-phenylindole.

For UNC-17 and choline acetyltransferase (ChAT) antibody staining, animals were placed on a slide, immobilized by pressing down on a coverslip, and frozen on dry ice for $30 \mathrm{~min}$. After removal of the coverslip (freeze-crack), the animals were fixed in methanol for $2 \mathrm{~min}$ and then acetone for $4 \mathrm{~min}$ at $4^{\circ} \mathrm{C}$. Samples were blocked for $1 \mathrm{hr}$ at room temperature (RT) with 10\% goat serum. Incubation with a 1:200 dilution of monoclonal UNC-17 antibody or $100 \mu$ l of ChAT antibody sera (J. Duerr and J. Rand, unpublished observations) was performed for $4 \mathrm{hr}$ to overnight at RT. Goat anti-mouse indocarbocyanine (Cy3) secondary antibody (1:400) (Jackson ImmunoResearch, West Grove, PA) was incubated for $4 \mathrm{hr}$ at RT.

Double antibody staining with UNC-18 and UNC-17 antibodies was performed in a two-step process. Freeze-cracked animals were fixed for $2 \mathrm{~min}$ in methanol followed by $4 \mathrm{~min}$ in acetone. Animals were blocked in 1\% BSA and then incubated with a 1:40 dilution of goat anti-UNC-18 at $4^{\circ} \mathrm{C}$ overnight. Secondary antibody of rabbit anti-goat $\mathrm{Cy} 3$ (1:200) was then incubated for $4 \mathrm{hr}$ at RT. Next, $10 \%$ goat serum was added to block residual rabbit anti-goat $\mathrm{Cy} 3$-binding sites. Animals were then incubated with UNC-17 mouse monoclonal antibody (1:200) for $4 \mathrm{hr}$ at RT followed by incubation with secondary antibody of goat anti-mouse $\mathrm{Cy} 2$ (1:600) for $4 \mathrm{hr}$ at RT.

Antibody staining with UNC-11 (Nonet et al., 1999) was performed on freeze-cracked animals fixed for $10 \mathrm{~min}$ in methanol at $-20^{\circ} \mathrm{C}$. UNC-11 antibody was incubated at 1:200 dilution overnight at $4^{\circ} \mathrm{C}$. Secondary antibody of goat anti-rabbit Cy3 (1:200) was incubated at RT for $4 \mathrm{hr}$.

Synaptotagmin antibody staining was performed on freeze-cracked animals prepared as described above except that animals were subsequently fixed in $2 \%$ paraformaldehyde on ice for $4 \mathrm{hr}$. Synaptotagmin antibody was incubated for $4 \mathrm{hr}$ at RT at a 1:50 dilution. Incubation with goat anti-rabbit Cy3 secondary antibody (1:200) (Jackson ImmunoResearch) was performed for $4 \mathrm{hr}$ at RT.

For the remainder of the antibodies used in these experiments (see below), animals were fixed with $0.4 \mathrm{ml}$ of Bouin's solution ( $75 \mathrm{ml}$ of saturated picric acid, $25 \mathrm{ml}$ of formalin, and $5 \mathrm{ml}$ of glacial acetic acid), $0.4 \mathrm{ml}$ of methanol, and $0.01 \mathrm{ml}$ of $\beta$-mercaptoethanol followed by incubations in primary antibodies for $2 \mathrm{hr}$ at RT and secondary antibodies for $2 \mathrm{hr}$ at RT. Primary antibody combinations included antiSynaptobrevin (1:50) (Nonet et al., 1998) and monoclonal GFP antibody (1:2000) (Clontech, Cambridge, UK); anti-RAB-3 (1:100) (Nonet et al., 1997) and polyclonal GFP antibody (1:1000) (Molecular Probes, Eugene, OR); and anti-Syntaxin (1:1000) (Saifee et al., 1998) and anti-RAB-3 (1:50) (Nonet et al., 1997). Secondary antibodies used were goat antirabbit Cy3 (1:500), goat anti-mouse Cy2 (1:200), goat anti-mouse Cy3 (1:500), and goat anti-rabbit Cy2 (1:200) (Jackson ImmunoResearch).

Microscopy. Immunofluorescent micrographs were obtained in a Zeiss Axioplan microscope and in a Zeiss LSM 410 confocal microscope.

The fluorescent intensity of individual DA and VA motor neurons was defined by comparison with flanking neurons in the ventral nerve cord (VNC) (i.e., VB, DB, and AS neurons). Staining intensity was scored in three categories: "wild type," in which DA and VA staining was comparable with that of adjacent cholinergic neurons; "reduced," in which DA and VA fluorescent intensity was visibly less bright than that of the reference neurons; "none," in which staining was not detectable or very faint.

Electron micrograph analysis. Existing sets of serial electron micrographs (EMs) of N2 (White et al., 1986) and of two unc-4(e120) animals (White et al., 1992) were examined to determine the numbers of presynaptic neurotransmitter vesicles in VA and VB motor neurons. Randomly selected prints were digitized on a flat bed scanner and recorded on 
compact disks. The number of vesicles in the VA and VB motor neurons was counted in each image (Adobe Photoshop). Sections that contained a thickening that resembled a PSD were then used to calculate the number of vesicles per PSD. For N2, four VA neurons (40 PSDs) and three VB neurons (43 PSDs) were analyzed. Two unc-4 animals were analyzed with a total of four VA neurons (54 PSDs) and four VB neurons (41 PSDs). The Mann-Whitney test was performed to determine whether the average number of vesicles per PSD was statistically different in the VAs versus the VBs in wild-type and unc-4-mutant backgrounds.

Thrashing assay. Adult animals were subjected to Chlorox and $\mathrm{NaOH}$ solution to isolate embryos (Sulston and Hodgkin, 1988). Embryos were placed on clean plates and incubated for $2 \mathrm{hr}$ at $25^{\circ} \mathrm{C}$. Hatched L1 animals were placed in M9 buffer in a 96-well microtiter plate. The number of times an active animal thrashed in a given direction was counted in a 2 min interval (Miller et al., 1996).

unc-4::SNB-1::gfp transgenic strains. Transgenic lines were obtained by injecting $p S B 126.65$ (unc-4::SNB-1::gfp) (M. L. Nonet, 1999) and pMH86 [the $d p y-20(+)$ cotransformation marker] (Clark et al., 1995) at $25 \mathrm{ng} / \mu \mathrm{l}$ (Mello and Fire, 1995). Standard genetic crosses were used to place the reporter gene into $u n c-4(w d 1)$ and $u n c-37(e 262)$ backgrounds.

Temperature-shift experiments. UNC-17 antibody staining was evaluated as a function of $u n c-4$ activity in DA and VA motor neurons. The double mutant unc-4(e2322ts) unc-104(e1265) was used for all temperature-shift experiments. For the analysis of unc-4(e2322ts) animals (Miller et al., 1992) at the permissive temperature, animals were raised at $16^{\circ} \mathrm{C}$ and then synchronized by Chlorox treatment (Sulston and Hodgkin, 1988). These animals were grown at the permissive temperature until the early adult stage. For analysis of $u n c-4 t s$ at the restrictive temperature, animals were raised at $25^{\circ} \mathrm{C}$, synchronized, and grown to the early adult stage. For the temperature-shift experiments, animals were raised at the first temperature ("embryo"), synchronized, shifted to the second temperature, and grown until the end of the L2 stage (determined by the appearance of the postderid cells; "L1-L2") (Sulston and Horvitz, 1977); these animals were then grown at the third temperature until the early adult stage ("adult"). UNC-17 antibody staining for these animals was performed as described above.

\section{RESULTS}

\section{UNC-4 is expressed in cholinergic motor neurons}

The homeodomain protein UNC-4 is expressed in specific classes of motor neurons. In the ventral nerve cord, UNC-4 is expressed in A-type motor neurons (the VAs and DAs) (Miller and Niemeyer, 1995) and in the VC motor neurons (Fig. 1). The VAs extend anteriorly directed axons within the ventral nerve fascicle, whereas the DAs send out commissural processes that also project anteriorly after entering the dorsal nerve cord (White et al., 1986). There are six VC motor neurons that innervate the vulval muscles in the midventral region (White et al., 1976, 1986). unc-4 is initially expressed in the VCs at the onset of vulval morphogenesis in the mid-L3 larval stage (data not shown). UNC-4 is also expressed in three SAB motor neurons (SABVL, SABV R, and SABD) (Miller and Niemeyer, 1995) that send out four anteriorly directed processes in the dorsal and ventral sublateral nerve cords adjacent to muscles in the head (White et al., 1986).

These four classes of "unc-4-motor neurons" (DA, VA, VC, and $\mathrm{SAB}$ ) are known to express ChAT and the vesicular acetylcholine transporter (VAChT or UNC-17) (J. Duerr, D. L. Frisby, and J. Rand, unpublished observations) and are therefore likely to use acetylcholine as an excitatory neurotransmitter. UNC-17 is an integral membrane component of neurotransmitter vesicles; a substantial fraction of the ChAT protein is also associated with vesicles in $C$. elegans (J. Duerr, unpublished observations). Here we show that the levels of UNC-17 and ChAT as well as that of other vesicle-associated proteins are regulated by unc-4 in these cholinergic motor neurons. [unc-4 is also expressed in the pharyngeal I5 motor neuron and in AVF neurons in the retrovesicu- lar ganglion (Miller and Niemeyer, 1995), but the effects of unc-4 mutations on SV proteins were not evaluated in these cells.]

\section{UNC-4 is required for expression of UNC-17 and ChAT in unc-4-motor neurons}

Antibody staining of wild-type animals for UNC-17 and ChAT produces a punctate pattern that is characteristic of presynaptic varicosities at en passant synapses. These UNC-17- and ChATcontaining structures are especially well resolved in the ventral and dorsal sublateral nerve cords in the head (Fig. 2) that contain tightly apposed axonal projections from two classes of cholinergic motor neurons, the SABs and SAAs (White et al., 1986) (J. Duerr, D. H. Hall, and J. Rand, unpublished observations). We observed a significant decrease in UNC-17 and ChAT staining in these processes in the null mutant $u n c-4(w d 1)$ (Table 1$) ; \sim 55 \%$ of the dorsal and ventral head sublateral nerve cords show wild-type levels of UNC-17 and ChAT staining in unc-4(wd1) animals. UNC-17 and ChAT staining is either reduced or absent in the remaining fasicles. [The complete elimination of UNC-17 and ChAT staining in some cases may mean that both the SAB and SAA axons are affected. However, we believe that the SAA defect must be indirect because UNC-4 is normally expressed in the SAB motor neurons but not in the SAAs.] Comparable decreases in UNC-17 and ChAT staining were also observed in three additional unc-4 alleles including the canonical null allele unc$4(e 120)$ as well as the missense mutants e26 and e2321 (Fig. 2, Table 1) (Winnier et al., 1999). In addition to the decrease in UNC-17 and ChAT antibody staining, we observed defects in axonal morphology; $10-15 \%$ of the dorsal and ventral head sublateral cords show misplaced, elongated, or branched processes in unc-4 and unc-37 mutants (data not shown). These morphologically abnormal SABs (and/or SAAs) also show reduced levels of UNC-17 and ChAT staining.

UNC-17 and ChAT levels were also evaluated in the VC axons that exit the ventral nerve cord to innervate vulval muscles (White et al., 1986). As shown in Figure 2, UNC-17 and ChAT staining of VC neuromuscular synapses is readily detected in the wildtype animal. However, in unc-4 mutants, UNC-17 and ChAT staining is substantially reduced in the VC motor neuron presynaptic zones (Fig. 2D, Table 1).

DA and VA motor neurons extend axons into the dorsal and ventral nerve cords, respectively (Fig. 1) (White et al., 1986). The active zones of these A-type motor neuronal processes are enmeshed in tightly packed fascicles and are thus not readily distinguished from the presynaptic regions of other overlapping motor neurons. To circumvent this problem, we evaluated UNC-17 and ChAT staining in the presence of a mutation in the unc-104 kinesin gene (Hall and Hedgecock, 1991). The unc104(e1265) mutation blocks anterograde axonal transport such that SVs accumulate in neuronal cell bodies where they can be detected by UNC-17 and ChAT antibody staining (Nonet et al., 1993). To aid in the identification of these $u n c-4$ motor neurons in the ventral nerve cord, we used an integrated unc-4 promoter-gfp line (wdIs5) to mark the DA and VA cell nuclei (Pflugrad et al., 1997). In animals containing wild-type UNC-4 activity, $\sim 80 \%$ of the VA and DAs (marked with GFP) show bright UNC-17 staining (Fig. 2, Table 1). However, in unc-4 mutants, we observed that only $\sim 10 \%$ of the VA and DA neurons show wild-type levels of UNC-17 staining. ChAT staining in the A-type motor neurons is also reduced in unc-4 mutants (Table 1). 

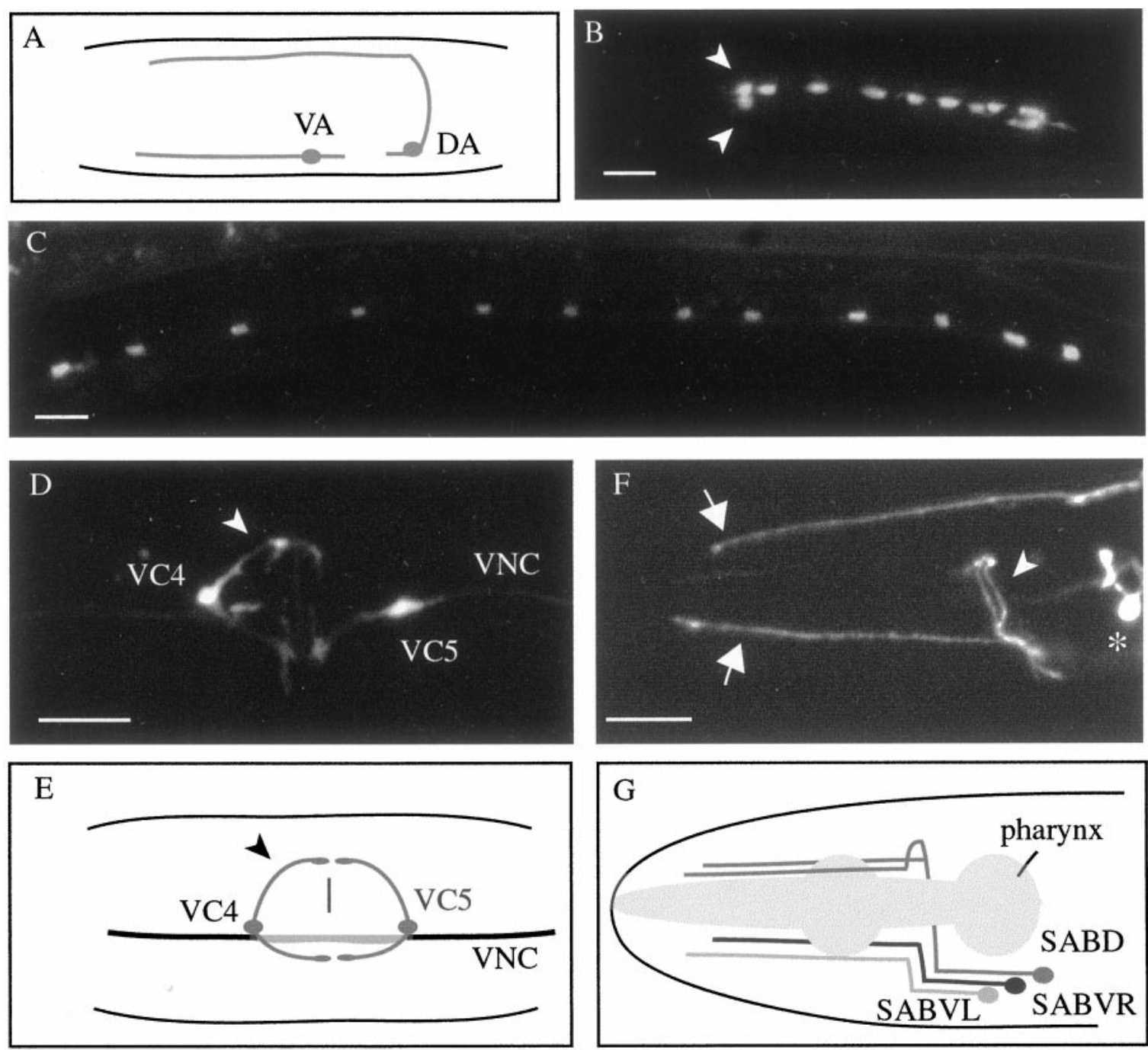

Figure 1. UNC-4::GFP is expressed in four classes of ventral cord motor neurons (DA, VA, VC, and SAB). The unc-4 promoter was fused to GFP for expression in transgenic animals (Pflugrad et al., 1997). A, Left lateral view showing a representative VA motor neuron with anteriorly directed axon in the VNC and a DA motor neuron with circumferential commissure and anteriorly directed axon in the dorsal nerve cord. $B$, Ventral view of L1 larva showing GFP accumulation in cell bodies of all nine DA motor neurons and in two SAB motor neurons (arrowheads). Axons are out of the plane of focus. $C$, Left lateral view of L2 larva showing GFP expression in all 12 VA motor neuron cell bodies. $D$, $E$, Ventral view of adult hermaphrodite showing GFP-positive VC4 and VC5 somata and VC1-VC6 axonal projections to vulval muscles (arrowhead). F, Left lateral view of GFP expression in anteriorly directed axonal projections (arrows) of SAB motor neurons. (Only two of four SAB processes are shown.) AVF processes in the nerve ring (arrowhead) and the 15 motor neuron (asterisk) in the posterior bulb of the pharynx also show UNC-4::GFP expression. $G$, Three SAB motor neurons innervating ventral (SABVL, SABVR) and dorsal (SABD) muscles in the head. Images shown in $D$ and $F$ are flattened stacks of optical sections collected in the confocal microscope. Scale bars, $10 \mu \mathrm{m}$. Anterior is to the left.

\section{UNC-37 functions with UNC-4 to maintain cholinergic proteins}

Other work from this laboratory has shown that the pattern of synaptic inputs to VA motor neurons (D. Hall, E. German, and D. Miller, unpublished observations) depends on unc-37 function (Pflugrad et al., 1997; Winnier et al., 1999). Here we show that unc-37 is also required for regulation of cholinergic protein expression in the VAs and in other unc-4 motor neurons. UNC-17 and ChAT antibody staining is substantially reduced in all four types of unc-4 motor neurons in mutants bearing the hypomorphic allele unc-37(e262) (Table 1) (Miller et al., 1993). UNC-17 and ChAT staining was not detectably altered in other classes of cholinergic motor neurons (DB, VB, and AS) in the ventral nerve cord (data not shown), indicating that this UNC-37 missense mutation specifically perturbs the regulation of these neurotransmitter vesicle-associated proteins in $u n c-4$ motor neurons.

\section{UNC-4 and UNC-37 regulate the levels of other vesicular proteins}

UNC-17 is an integral vesicular membrane protein (Alfonso et al., 1993). Although ChAT is a cytosolic enzyme, a significant fraction of ChAT protein is associated with the vesicles (Duerr, unpublished observations). Because these two vesicular proteins are downregulated in $u n c-4$ and $u n c-37$ animals, we wondered whether other vesicular proteins are also affected in these mutants. We used specific antibodies to assess the effects of unc-4 and $u n c-37$ activity on the levels of three additional proteins that are associated with synaptic vesicles: (1) Synaptotagmin, an integral vesicular protein proposed to be involved in calciummediated SV release and vesicle endocytosis (Nonet et al., 1993), (2) Synaptobrevin, an integral vesicular protein that is a component of the SNARE complex (Nonet et al., 1998), and (3) RAB-3, a GTPase that associates with vesicles before fusion (Nonet et al., 

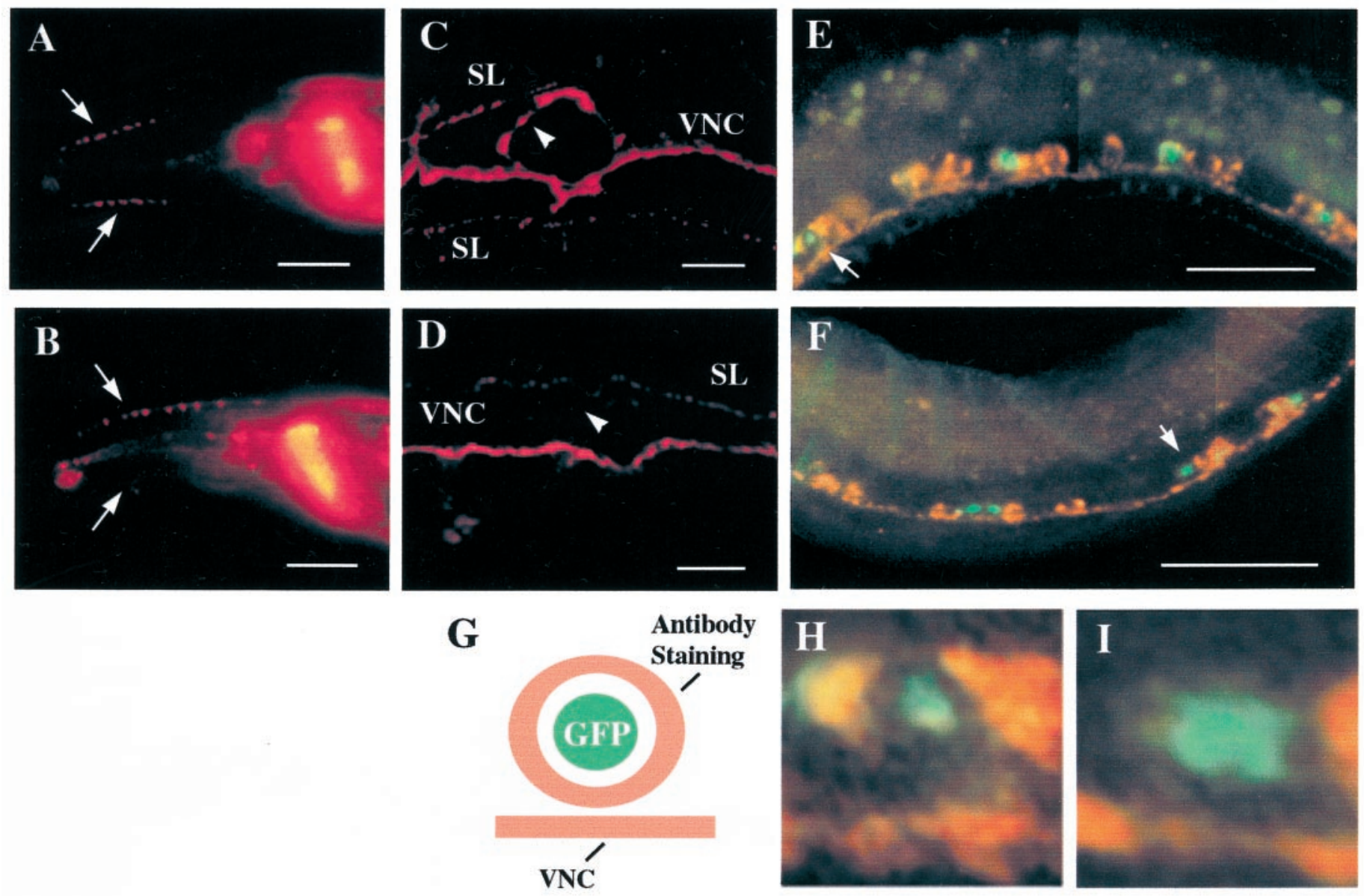

Figure 2. UNC-17 expression in motor neurons is decreased in unc-4 mutants. $A$, Left lateral view shows punctate pattern of UNC-17 antibody staining in the SAB-containing nerve cords in the head region of a wild-type animal. Arrows point to dorsal and ventral left sublateral processes. $B$, Punctate UNC-17 staining is reduced or eliminated in many of the head sublateral processes in unc-4(e120)-mutant animals. Note the absence of UNC-17 staining in the left ventral process containing SABVL. $C$, Ventral view of UNC-17 expression in wild-type VC axons that innervate the vulval muscles (arrowhead) is shown. D, UNC-17 staining of VC vulval projections is eliminated or reduced in unc-4(e120) mutants, but UNC-17 staining of other cholinergic processes in the VNC and ventral sublateral $(S L)$ nerve cords is not noticeably affected. $E-I$, Left lateral views are shown. The unc-104 kinesin mutation was used to localize UNC-17 to the soma of ventral cord motor neurons (Hall and Hedgecock, 1991; Nonet et al., 1993). The nuclei of DA and VA motor neurons also express UNC-4::GFP (see $G$ ) (Pflugrad et al., 1997). E, $G, H$, In animals that are wild-type for unc-4, strong UNC-17 antibody staining is visible in the cytoplasm of cholinergic motor neurons. $F, I$, In unc-4(e120) mutants, cytoplasmic UNC-17 staining is substantially reduced in the unc-4::gfp-expressing DA and VA motor neurons. $H$ and $I$ are enlargements of single VA neurons from $E$ and $F$ (arrows), respectively. Scale bars, $10 \mu \mathrm{m}$. Anterior is to the left.

1997). In all three cases, the levels of antibody staining were substantially reduced in DA and VA motor neurons in unc-4 and unc-37 mutants (Fig. 3). Thus, our results show that five different vesicular or vesicle-associated proteins (UNC-17, ChAT, Synaptotagmin, Synaptobrevin, and RAB-3) are downregulated in animals with loss-of-function mutations in either the $u n c-4$ or unc-37 genes.

\section{Nonvesicular proteins are not affected in unc-4 and unc-37 mutants}

To determine whether $u n c-4$ and $u n c-37$ affect all proteins involved in exocytosis or whether this effect is restricted to vesicular proteins, we examined levels of Syntaxin (Ogawa et al., 1998; Saifee et al., 1998), a neuronal membrane component of the SNARE complex, as well as that of UNC-18 (Hosono et al., 1992; Geppert et al., 1994), a cytoplasmic protein implicated in regulating the docking of vesicles via its association with Syntaxin. Expression levels of these proteins were scored in the VC axonal projections and in the SAB-containing dorsal and ventral sublateral nerve cords in the head. UNC-18 is readily detected in axonal projections of the $\mathrm{VC}$ motor neurons in wild-type as well as in $u n c-4$ and $u n c-37$ animals. This finding stands in contrast to our observation that UNC-17 expression in the VCs is only seen in wild-type animals (Fig. 4, Table 2).

Although Syntaxin expression is not detectable in the VCs, we did observe high levels of Syntaxin as well as UNC-18 staining in the head sublaterals in both $u n c-4$ and $u n c-37$ mutants (Table 2). In this case, it is possible that at least some of the Syntaxin and UNC-18 staining in the head sublaterals may be caused by the SAA axons that normally fasiculate with SAB processes. The differential effects of $u n c-4$ and $u n c-37$ mutations on vesicular proteins are clearly seen in SAB (or SAA) axons with branching or guidance defects that stain for Syntaxin and UNC-18 but that do not show expression of either RAB-3 or UNC-17 (data not shown). These results indicate that specific synaptic membrane and docking regulatory proteins are expressed at wild-type levels in $u n c-4$ and $u n c-37$ mutants whereas vesicular proteins are downregulated.

We also assessed the potential effects of the unc-4 mutations on 
Table 1. UNC-17 and ChAT antibody staining

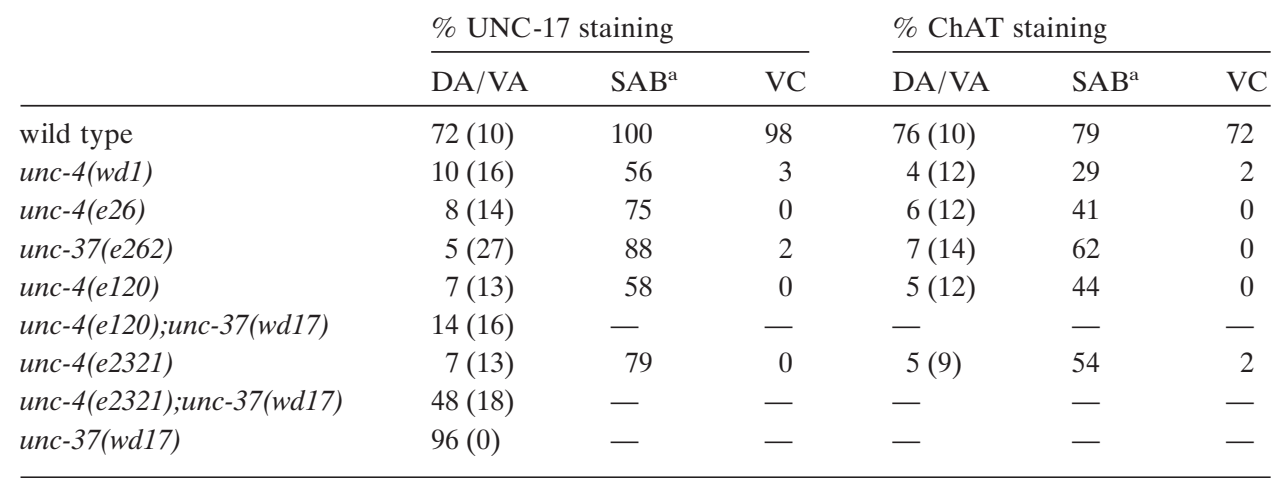

$\%$, Percentage of neurons that show wild-type levels of antibody staining. Numbers in parentheses refer to DA/VA motor neurons showing reduced or intermediate levels of antibody staining (see Materials and Methods). UNC-17 and ChAT expression in DA and VA motor neurons was scored as described below (see Fig. 2). Neurons were scored for DAs/VAs $(126 \leq n \leq 416)$. VC vulval varicosities $(n=60)$ and SAB-containing processes $(n=120)$ were scored (see Fig. 8).

- , Not scored.

a SAB-containing head sublateral nerve cords also include axonal processes from SAA neurons (White et al., 1986).

Figure 3. Vesicular protein levels depend on unc-4 and unc-37 activity. Antibodies to RAB-3 (A), Synaptobrevin $(B)$, and Synaptotagmin $(C)$ were used to detect these vesicular proteins in the DA and VA motor neurons in wild-type and in unc-4- and unc-37-mutant animals. (Methods were as described for Fig. 2.) Vertical bars in the histograms indicate the percentage of DA and VA motor neurons showing intense antibody staining (white) plus the percentage of animals showing reduced or intermediate levels of staining (gray) (see Materials and Methods). At least 125 VA and DA neurons were scored for each strain and for each vesicular protein antibody. All unc-4 and unc-37 mutants in these experiments are loss-of-function alleles.

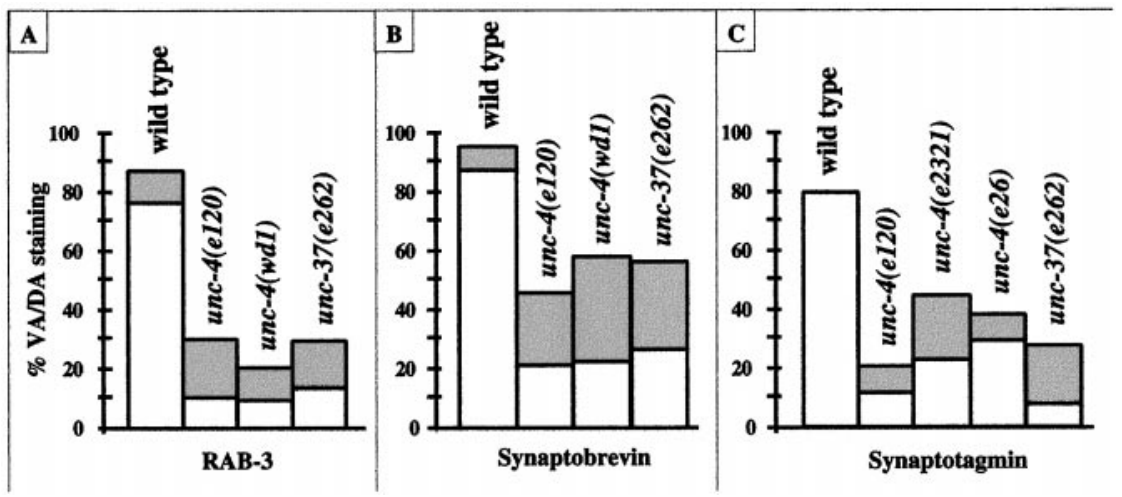

UNC-11, a component of the endocytic machinery. The C. elegans unc-11 gene encodes a homolog of the clathrin adaptor protein AP180 (Nonet et al., 1999). In the missense allele unc11(n2954), the UNC-11 protein is restricted to motor neuron cell bodies and does not accumulate at presynaptic termini. This property of the mutant protein was used to score UNC-11 expression in DA and VA motor neurons in the ventral nerve cord. Approximately $90 \%$ of ventral cord motor neurons including the DAs and VAs stain positive for UNC-11 in the unc-11 single mutant as well as in the unc-4;unc-11 double mutant (data not shown). Thus, the unc-4 mutation does not lower the levels of UNC-11 protein. This conclusion is also consistent with electron micrographs of VA motor neuron presynaptic zones that do not show the characteristically enlarged vesicular structures that are seen in unc-11 mutants (data not shown) (Nonet et al., 1999).

\section{Neurotransmitter vesicles are decreased in unc-4 mutants}

EM reconstruction of $u n c-4(e 120)$ has revealed that the VA motor neurons receive incorrect inputs but are otherwise morphologically wild-type with anteriorly directed axons that make normallooking neuromuscular synapses (White et al., 1992). The axonal diameters of VA motor neurons are similar to those of adjacent VB motor neurons (data not shown). We have now reexamined these EM data to quantitate the number of vesicles in the VA motor neurons. In wild-type animals, the average number of vesicles in a section that contains a VA motor neuron PSD is comparable with the average number of PSD-adjacent vesicles in VB motor neurons ( 40) (Fig. 5) (White et al., 1986). In contrast, vesicle number in the active zones of VAs is $40 \%$ lower than that of the VBs in unc-4(e120) animals (White et al., 1992). This difference is statistically significant (see Materials and Methods). Vesicle numbers within the intersynaptic regions of VAs and VBs are not significantly different between wild-type and unc-4 animals (data not shown). This finding is important because it excludes the possibility that the reduced number of vesicles that we observe at the presynaptic zones of VA motor neurons in unc- 4 mutants is caused by the redistribution of vesicles within the intersynaptic regions as is the case in $r a b-3$ mutants (Nonet et al., 1997). Therefore, we conclude that there are fewer vesicles in the VA motor neurons in unc-4 mutants and that this reduction is correlated with the reduced levels of vesicular protein antibody staining that we have observed in the light microscope.

\section{Reduced vesicular protein staining is correlated with functional defects in unc-4 neurons}

The ventral nerve cord of the newborn L1 larva contains a simple motor neuron circuit comprised of two classes of excitatory, cholinergic motor neurons (DA and DB) and one class of inhibitory, GABAergic motor neuron (DD) (White et al., 1986; McIntire et al., 1993). [VA motor neurons are not added to the backward movement circuit until the L1-L2 molt (Sulston and Horvitz, 1977)]. Our results showing that SV levels are drastically reduced in the DA motor neurons in $u n c-4$ and unc-37 mutants 

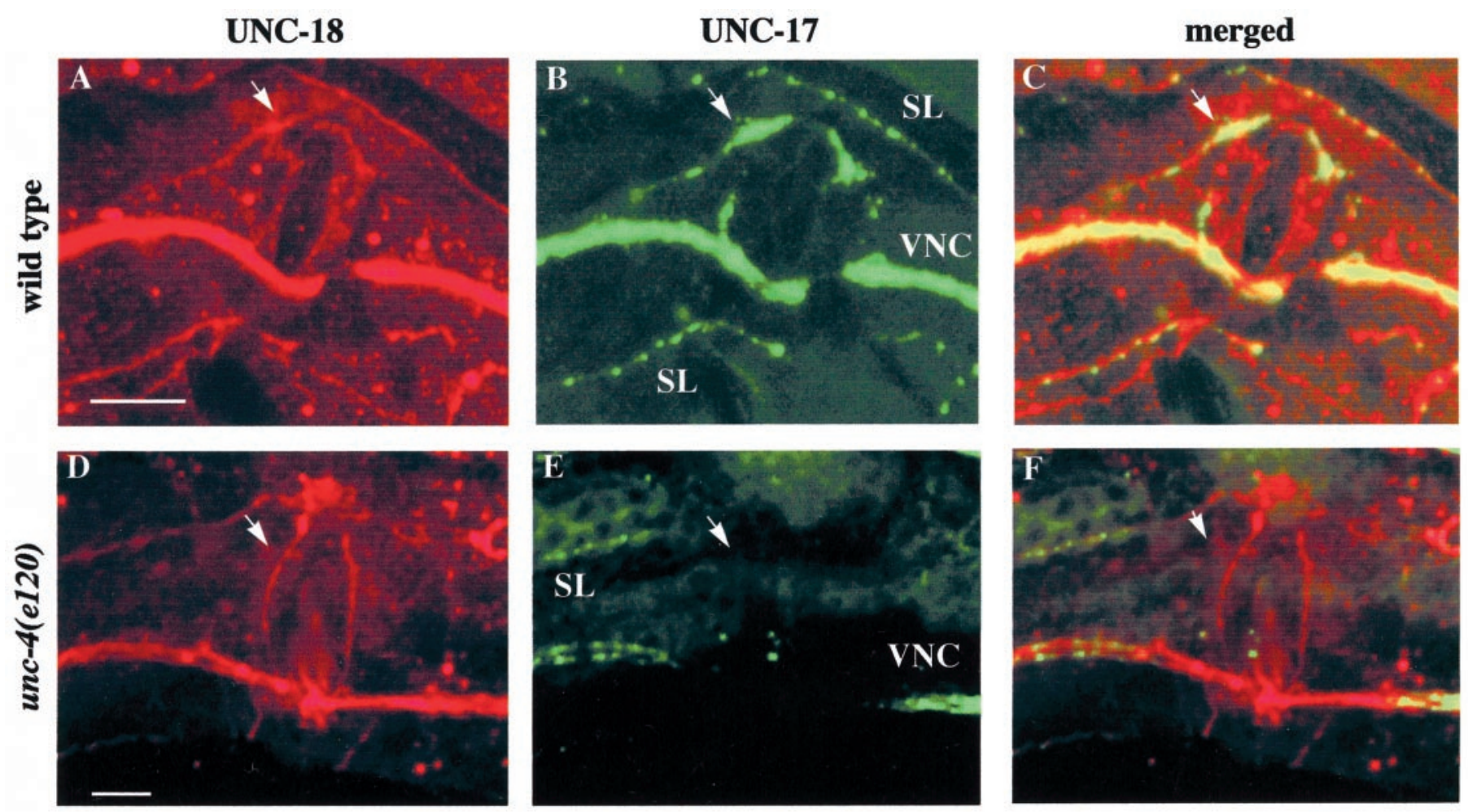

Figure 4. UNC-18 expression is not altered in unc-4 and unc-37 mutants. A ventral view of the vulval area is shown. Anterior is to the left. Double antibody staining was performed with UNC-17 and UNC-18 antibodies. $A, D$, UNC-18 antibody (red) stains the axonal processes of the VCs in a diff use pattern (arrow). B, E, UNC-17 (green) is detected in VC varicosities associated with vulval muscles (arrow). C, F, Merged images show overlapping UNC-17 and UNC-18 antibody staining (yellow). $A-C$, In wild type, the UNC-17 and UNC-18 antibodies colocalize to VC axonal projections. $D-F$, In unc-4 mutants, UNC-18 $(D, F)$ but not UNC-17 $(E, F)$ (arrow) is detectable in VC axonal processes. All images are stacked confocal sections and were merged in Photoshop $(C, F)$. Scale bar, $A-C, D-F, 10 \mu \mathrm{m}$.

Table 2. Comparison of vesicular proteins RAB-3 and UNC-17 with nonvesicular proteins Syntaxin and UNC-18

\begin{tabular}{llcc} 
& \multicolumn{2}{c}{$\mathrm{SAB}^{\mathrm{a}}$} & $\mathrm{VC}$ \\
\cline { 2 - 3 } & $\% \mathrm{RAB}-3 /$ Syntaxin $^{\mathrm{b}}$ & \multicolumn{2}{c}{$\% \mathrm{UNC}-17 / \mathrm{UNC}^{-18^{\mathrm{c}}}$} \\
\hline wild type & 100 & 100 & 100 \\
unc-4(e120) & 57 & 60 & 0 \\
unc-4(wd1) & 59 & 58 & 0 \\
unc-37(e262) & 59 & 64 & 0
\end{tabular}

aSAB-containing head sublateral nerve cords also include axonal processes from SAA neurons (White et al., 1986).

${ }^{\mathrm{b}}$ Percentage of Syntaxin-positive SAB-containing processes $(45<n<147)$ that have wild-type RAB-3 staining.

${ }^{\mathrm{c}}$ Percentage of UNC-18-positive VC axons $(28 \leq n \leq 40)$ and SAB-containing fasicles $(45 \leq n \leq 147)$ that have wild-type UNC-17 staining (for scoring, see Fig. 8).

predict that newly hatched L1 larvae should show impaired movement because of the lowered neurotransmitter signaling capacity of $\sim 50 \%$ of the excitatory ventral cord motor neurons in these animals. We used a liquid "thrashing" assay (Miller et al., 1996) to confirm that unc-4 and unc-37 L1 larvae are substantially less active than are wild type (Fig. 6). The simplest interpretation of this effect is that the excitatory function of the DA motor neurons is compromised by $u n c-4$ and $u n c-37$ mutations. EM reconstruction of DA motor neurons in the adult indicates that these cells are not miswired in $u n c-4$ mutants and appear otherwise morphologically normal (White et al., 1992). Therefore, we attribute the movement defect of unc-4 L1 larvae to the observed reduction in neurotransmitter vesicles in these cells.
Although the SAB motor neurons make clearly visible synapses adjacent to muscles in the head, their role in locomotion has not been defined (J. Duerr, D. H. Hall, and J. Rand, unpublished observations). Recently, Zhao and Nonet (2000) reported that mutants with reduced levels of synaptic transmission show SAB axonal sprouting or branching defects. We have also observed this phenomenon in a significant number $(10-15 \%)$ of SAB axons of $u n c-4$ and unc-37 mutants. Furthermore, of the SAB axons that do exhibit sprouting defects, most also show reduced levels of vesicular protein expression (data not shown). Therefore, our results are consistent with the model in which the lowered levels of neurotransmitter vesicles in $u n c-4$ and $u n c-37$ mutants result in a significant reduction in SAB synaptic activity.

The VC motor neurons innervate the vulval muscles to modulate egg-laying behavior (White et al., 1986; Waggoner et al., 1998). We have observed that unc-4 and unc-37 mutants are mildly resistant to serotonin-induced egg laying (Trent et al., 1983) and also show significantly smaller brood sizes than are seen in wild type (data not shown). These mutant phenotypes could be indicative of VC dysfunction in unc-4 and unc-37 mutants.

The VA motor neurons arise after hatching in the first larval stage and function in the backward movement circuit in larvae and adults (Sulston and Horvitz, 1977; Chalfie et al., 1985). That VA motor neuron activity is affected in unc-4 and unc-37 mutants is evident in the striking backward movement defects that these animals display (White et al., 1992). The inability of unc-4 mutants to crawl backward has been attributed to a miswiring defect 

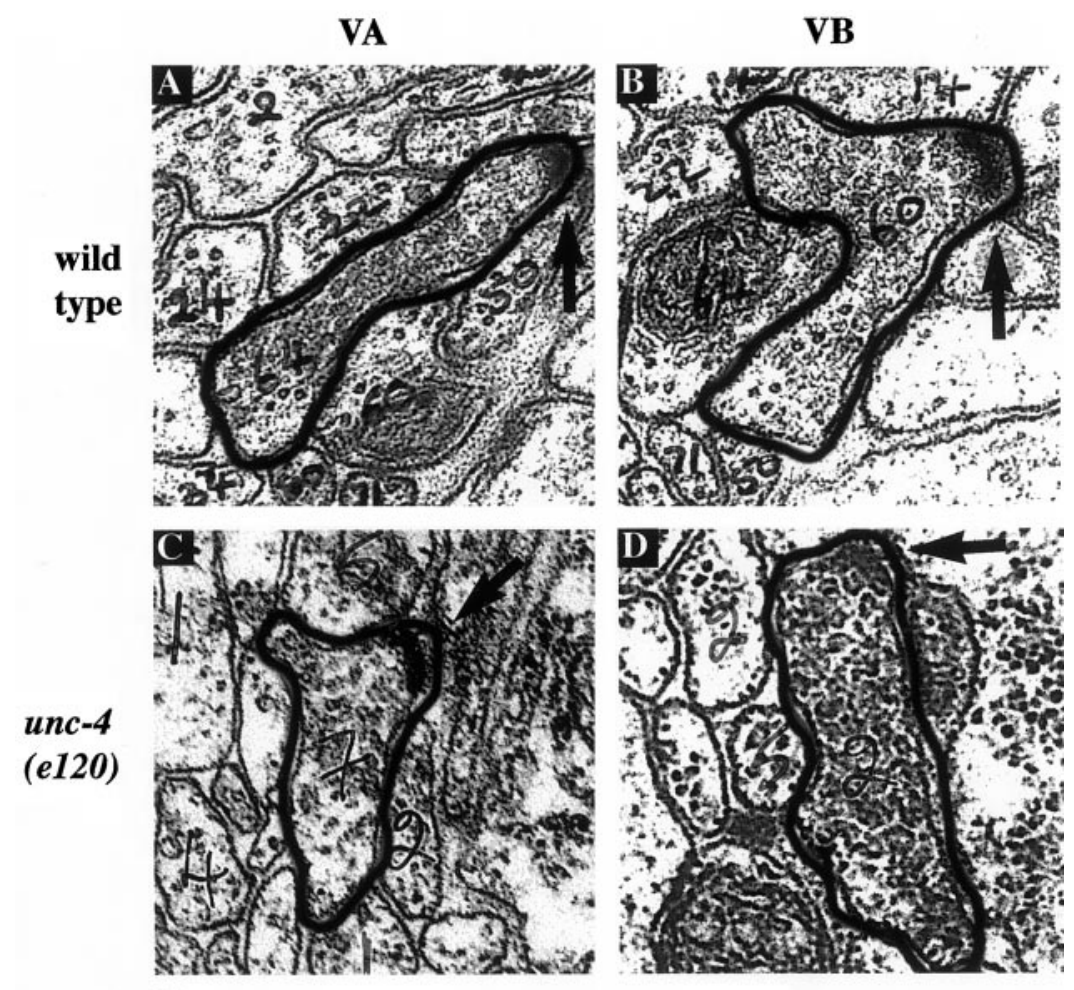

Figure 5. Reduction of presynaptic vesicles in VA motor neurons in unc-4(e120). Vesicles were counted in EM photos of VA and VB cross sections showing PSDs (arrows). $A, B$, Presynaptic regions of VA $(A)$ and $\mathrm{VB}(B)$ motor neurons in wild type are shown. $C, D$, Fewer vesicles are seen in the presynaptic region of VAs $(C)$ versus $\operatorname{VBs}(D)$ in unc4(e120). The circumference of individual VA and VB motor neuron processes is outlined with a heavy black border. Handwritten numbers on these prints were used to trace individual neurons through these serial sections for reconstruction of the wild-type and unc-4(e120) ventral nerve cords (White et al., 1986, 1992). E, Plot of vesicles per PSD in VA and VB motor neurons in wild-type versus two unc-4-mutant animals $[u n c-4(1), u n c-4(2)]$ is shown. Application of the MannWhitney statistical test indicates that the decreased number of vesicles in VA motor neurons in unc-4(e120) is significantly different from that of the VBs $\left({ }^{*} p<0.005 ;{ }^{* *} p \ll\right.$ 0.001). Error bars indicate SD.

\section{$\mathbf{E}$}

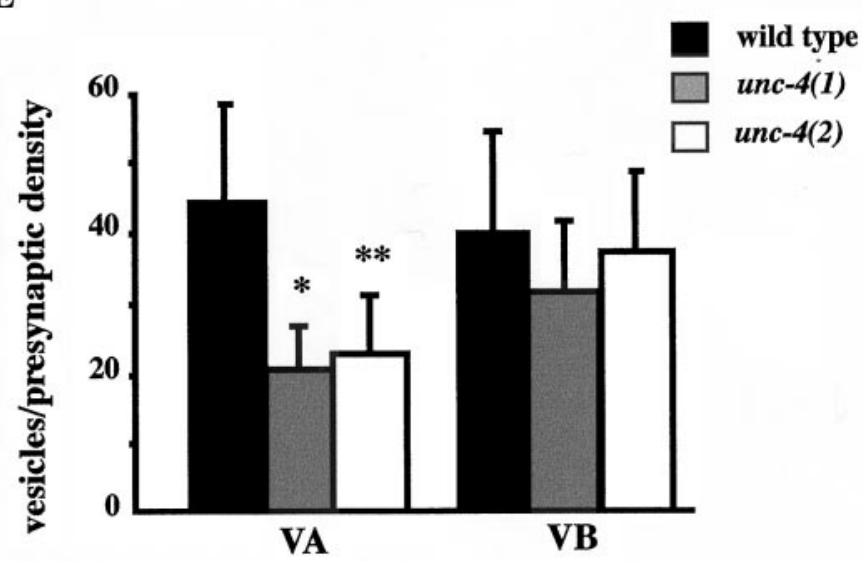

in which VA motor neurons receive synaptic inputs from inappropriate command interneurons (White et al., 1992). It is also possible that the depletion of neurotransmitter vesicles in the VAs by unc-4 and unc-37 mutations could contribute to this locomotory defect (see Discussion).

\section{UNC-4- and UNC-37-dependent transcriptional repressor function is required to maintain normal levels of vesicular proteins}

Having established that neurotransmitter proteins and the vesicles into which they assemble are substantially reduced in specific motor neurons in unc-4 and unc-37 mutants, we next performed experiments to address the molecular mechanism of this effect.

Missense mutations in the UNC-4 engrailed-like repressor domain (eh1) have been shown to inactivate UNC-4 repressor activity and to perturb interactions with UNC-37 (Winnier et al., 1999). We tested two of these eh 1 mutations, $e 2321$ and $e 26$, and discovered that both result in reduced levels of UNC-17 and ChAT staining in unc-4 motor neurons (Table 1). Furthermore, unc-37(wd17), an allele-specific Unc-4 suppressor mutation in the

UNC-37 WD repeat domain (Miller et al., 1993), restores physical interaction with the e2321-mutant UNC-4 protein and elevates levels of UNC-17 and ChAT staining in e2321-mutant animals (Table 1) (Winnier et al., 1999). However, UNC-17 and ChAT staining is not restored in the null allele unc-4(e120), which is also not suppressible by the $u n c-37(w d 17)$ mutation (Winnier et al., 1999). Thus, we conclude that UNC-4 regulation of UNC-17 and ChAT protein levels depends on physical interactions with an intact UNC-37/Groucho protein.

The 22321 -mutant animals also show reduced thrashing rates as L1 larvae (Fig. 6). The unc-37(wd17) mutation suppresses this effect for the $e 2321$ mutation but not for the nonsuppressible unc-4(e120) null allele. The concomitant effects of the unc-37 suppressor mutation on vesicular protein expression and on L1 motility substantiate a model in which DA motor neuron function depends on UNC-4 interactions with UNC-37.

These results are consistent with a model in which the UNC4-UNC-37 complex represses transcription of a downstream gene that in turn exerts a negative effect on synaptic vesicle levels. 


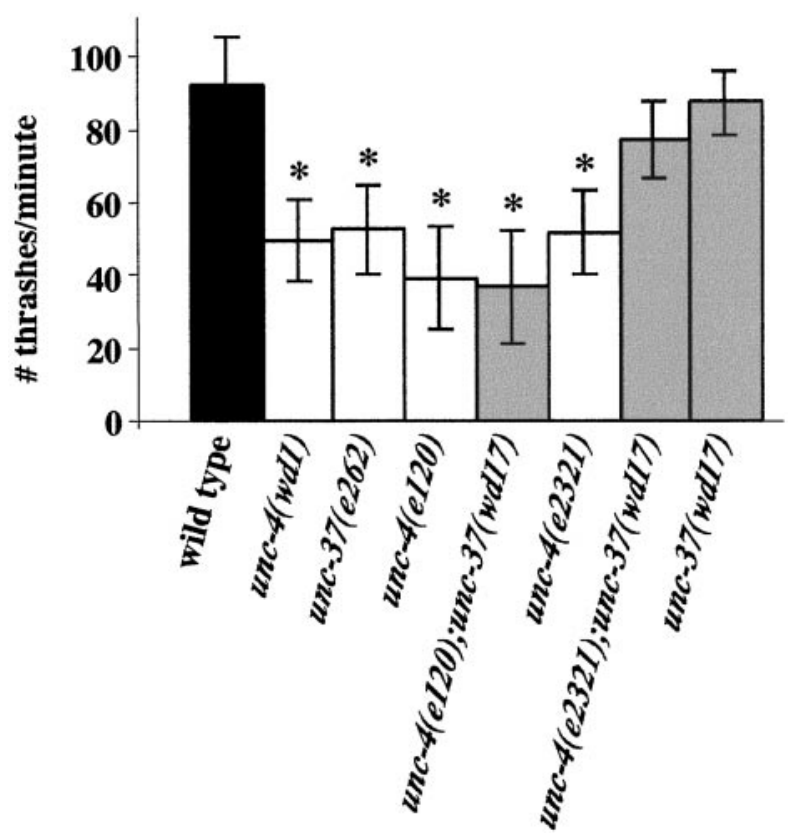

Figure 6. Thrashing rates of L1 animals. The total number of body thrashes was counted during a 2 min period. A thrash was scored as a movement of the animal's body in either the dorsal or ventral direction. Error bars are \pm SD. Values that are statistically different from wild type using the Student's $t$ test $(p \ll 0.001)$ are marked with an asterisk. Results of experiments performed with $u n c-37(w d 17)$ strains are denoted with gray shading.

Experiments described in the next section indicate that this UNC-4-UNC-37 target gene (gene $x$ ) downregulates SV protein levels via a post-transcriptional mechanism (see Fig. 9).

\section{Vesicular proteins are regulated at a post-transcriptional level}

unc-17 and cha-1 are arranged in an operon where they share a common promoter and first untranslated exon (Alfonso et al., 1994) A $3.2 \mathrm{~kb}$ promoter element from this upstream region is sufficient to drive expression of GFP in virtually all cholinergic neurons including excitatory motor neurons in the ventral cord (D. Frisby and J. Rand, unpublished observations). Expression of the unc-17-cha-1 promoter::gfp reporter gene in unc-4 motor neurons is not altered by loss-of-function mutations in either unc-4 or unc-37 (Fig. 7). Thus, the unc-17-cha-1 promoter region does not respond to changes in $u n c-4$ and $u n c-37$ activity. In contrast, expression of unc-17-cha-1 promoter::gfp in these neurons does depend on the cell autonomous activity of the UNC-3 protein that has been shown to function as a regulator of unc-17cha-1 transcription (K. L. Lickteig, D. L. Frisby, J. Duerr, D. M. Miller, and J. Rand, unpublished observations). These findings argue against a mechanism in which $u n c-4$ and unc-37 mutations affect $u n c-17$ and cha-1 transcription.

To determine whether other vesicular proteins are also regulated at a post-transcriptional level by unc-4 and unc-37, we evaluated expression of a GFP-tagged Synaptobrevin driven by the unc-4 promoter (M. L. Nonet, 1999). This construct (unc-4p::SNB-1::gfp) contains the full-length Synaptobrevin protein with a $\mathrm{C}$-terminal GFP tag. Expression of this transgene produces a punctate pattern of GFP staining that is correlated with the localization of SNB-1::GFP at the PSDs of unc-4 motor neurons. This pattern is especially well resolved in the SAB processes in the head and in $\mathrm{VC}$ axons that exit the nerve cord to innervate vulval muscles (Fig. 8). To determine whether the regulation of Synaptobrevin by unc-4 and unc-37 is independent of the Synaptobrevin promoter, we placed the unc-4p::SNB-1::gfp construct in unc-4- and unc-37-mutant backgrounds. In these animals, expression of GFP-tagged Synaptobrevin is clearly reduced in the axonal projections of the $\mathrm{VC}$ and $\mathrm{SAB}$ motor neurons (Fig. 8). A similar reduction is seen for UNC-17 and ChAT antibody levels in these cells in $u n c-4$ and $u n c-37$ mutants (compare Table 1, Fig. 8E). Because unc-4 expression is not regulated by $u n c-4$ or $u n c-37$ (Miller et al., 1993; Miller and Niemeyer, 1995), it follows that the decreased levels of SNB-1::GFP in these mutants is not a result of $u n c-4$ or $u n c-37$ regulation of the $u n c-4$ promoter. Therefore, $u n c-4$ and $u n c-37$ regulation of Synaptobrevin expression does not occur via a transcriptional mechanism but must depend on some feature of the Synaptobrevin-transcribed sequence. This finding parallels the observation above that UNC-17 and ChAT are also likely to be regulated by $u n c-4$ and $u n c-37$ at a post-transcriptional level and therefore favors a model in which all of the affected vesicular proteins are similarly regulated.

\section{Vesicular protein levels are developmentally regulated by unc-4}

We performed temperature-shift experiments with the temperature-sensitive mutant unc-4(e2322ts) (Miller et al., 1992) to define the developmental periods in which $u n c-4$ is required to maintain wild-type levels of the vesicular protein UNC-17 in DA and VA motor neurons. DA motor neurons are generated in the embryo; VA motor neurons arise after hatching in the late L1 larva (Sulston and Horvitz, 1977; Sulston et al., 1983). When e2322ts animals are maintained at the permissive temperature $\left(16^{\circ} \mathrm{C}\right)$ throughout development, both the DA and VA motor neurons express high levels of UNC-17 protein (Table 3). Growth at the restrictive temperature $\left(25^{\circ} \mathrm{C}\right)$ results in substantially lower levels of UNC-17 expression (18\% of DAs and 6\% of VAs). Temperature-shift experiments have revealed, however, that $u n c-4$ function is specifically required during the early developmental periods in which DA and VA motor neurons differentiate but is not necessary in older larvae or adults for maintaining normal levels of UNC-17 protein. For example, exposure of L1 and $\mathrm{L} 2$ larvae to $25^{\circ} \mathrm{C}$ results in UNC-17 staining in only $30 \%$ of the VAs, whereas exposure of older animals (L3 to adult) does not reduce UNC-17 expression in these cells. DA motor neurons are similarly sensitive to restrictive temperature. In this case, however, DAs in both embryos and L1-L2 larvae are affected with only $\sim 20 \%$ of the DAs showing UNC-17 expression; exposure of older animals to the restrictive temperature has no effect (Table 3).

\section{DISCUSSION}

\section{unc-4 and unc-37 regulate vesicle biogenesis or stability}

By what mechanism does the unc-4-unc-37 pathway regulate vesicle number in the affected cholinergic motor neurons?

Our results exclude a model in which the decreased number of synaptic vesicles at the PSD is caused by defective anterograde transport or localization in $u n c-4$ and $u n c-37$ mutants. First, we showed that SV protein levels, as assayed in the cell soma of DA and VA motor neurons, are still diminished by unc-4 and unc-37 mutations even when vesicle translocation to the synapse is 


\section{wild type}

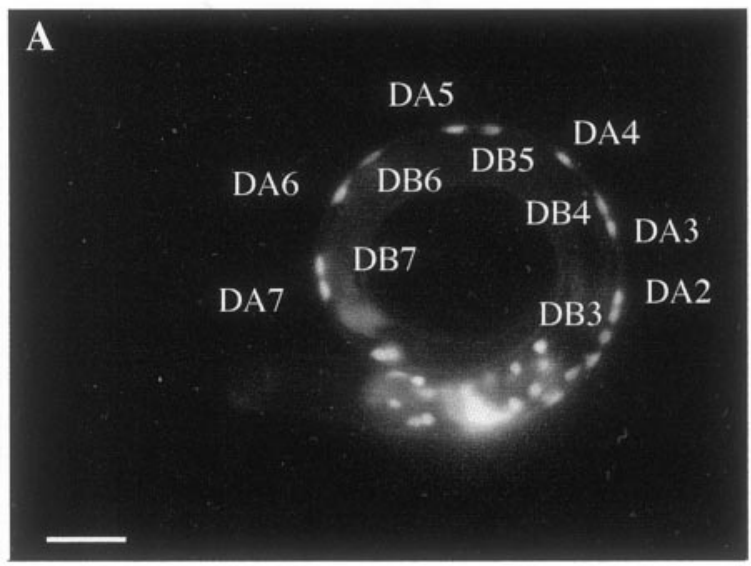

L2

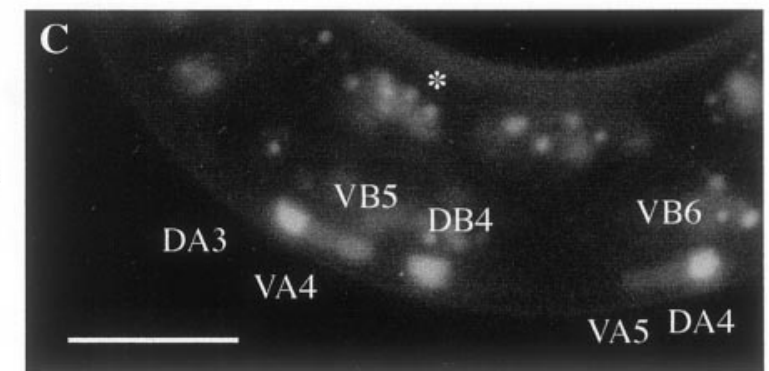

unc-4(e120)
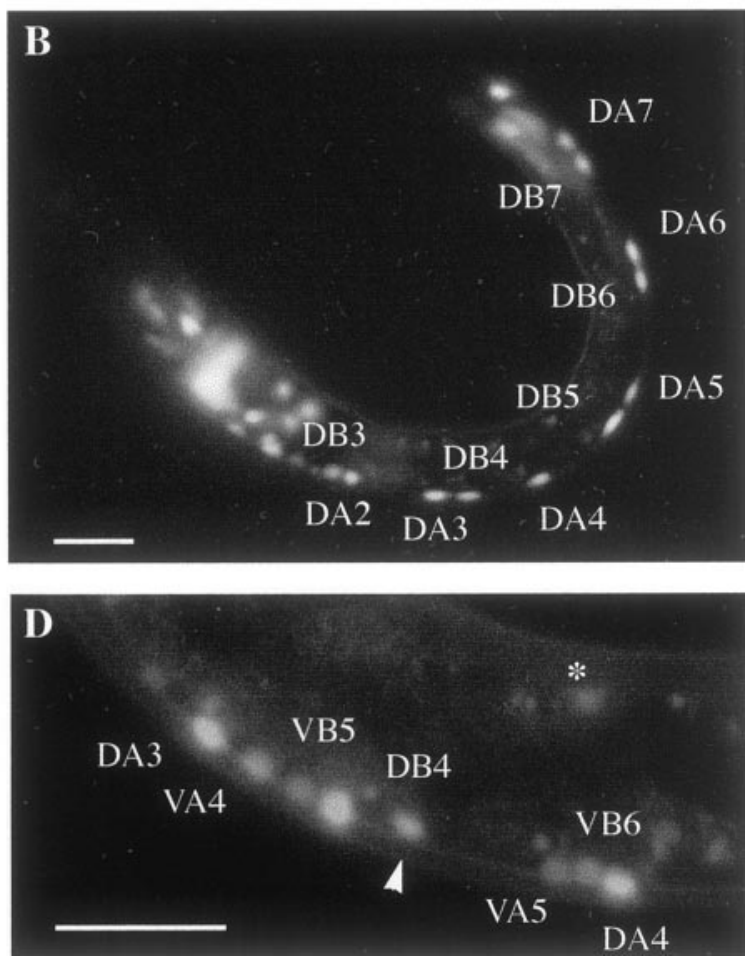

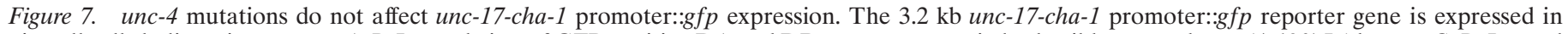

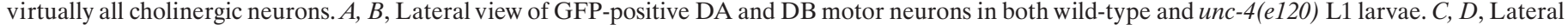

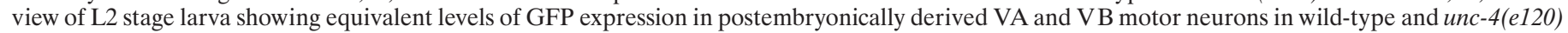

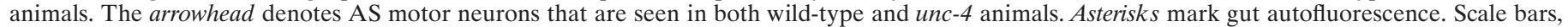
$10 \mu \mathrm{m}$.

blocked by a mutation in the unc-104 kinesin gene (Hall and Hedgecock, 1991). Second, our analysis of EM serial sections did not detect any evidence to support a model in which decreased accumulation of SVs at the PSD is caused by their redistribution to intersynaptic regions as occurs in $r a b-3$ null mutants (data not shown) (Nonet et al., 1997). Although RAB-3 protein levels are reduced in $u n c-4$ and $u n c-37$ mutants, we assume that the residual level of RAB-3 expression in the affected motor neurons of these animals is sufficient for normal SV localization.

In an alternative model, vesicle number could be effectively diminished by a dramatic increase in exocytosis. If that were the case, mutations in the unc-13 gene, which is required for vesicle fusion (Richmond et al., 1999), should prevent SV depletion by this mechanism in $u n c-4$ and $u n c-37$ mutants. We observed the opposite result, however; the elimination of $u n c-13$ activity did not restore the SV protein UNC-17 to normal levels in either unc-4- or unc-37-mutant backgrounds (data not shown). Thus, our results exclude the possibility that enhanced rates of vesicle exocytosis account for the reduced levels of SV proteins in unc-4and unc-37-mutant motor neurons.

Lastly, our results argue against the possibility that defective vesicle endocytosis effectively diminishes the steady-state level of PSD-localized vesicles in $u n c-4$ and $u n c-37$ mutants. unc-4 mutants are not affected in their expression of UNC-11, a homolog of the endocytic protein AP180 (data not shown). Although AP180 is not essential for endocytosis, it does play a role in regulating clathrin coat size; unc-11-mutant motor neurons show vesicles that are normal in number but with an enlarged diameter (Nonet et al., 1999). EM analysis of unc-4 mutants does not reveal these large recycling intermediates or other defects commonly associated with mutations in the endocytic machinery (i.e., increased axonal diameter, membrane infoldings, collared vesicles) (Cremona and De Camilli, 1997). In addition, our results showing that SV levels are decreased even when anterograde transport is blocked by the unc-104 mutation indicate that nascent SVs are affected and therefore argue against the possibility that this reduction is caused by defective endocytosis in $u n c-4$ and $u n c-37$ mutants.

We favor a model in which unc-4 and unc-37 regulate some aspect of vesicle biogenesis or stability. Genetic ablation of Synapsin in cultured neurons and in knock-out mice results in a significant reduction of vesicles and SV proteins but not other synaptic membrane or cytosolic proteins (Li et al., 1995; Rosahl et al., 1995; Takei et al., 1995). This effect has been attributed to an increased rate of vesicle turnover. The striking similarity of this phenotype to that of unc-4 and unc-37 mutants is consistent with the formal hypothesis that unc-4 and $u n c-37$ are indirectly responsible for maintaining Synapsin protein levels in specific neurons. The recent identification of a C. elegans Synapsin homolog (Kao et al., 1999) offers the possibility of experimentally testing this model.

\section{Neuronal function depends on post-transcriptional regulation of SV protein expression}

Because the $u n c-4$ and $u n c-37$ mutations that reduce SV protein levels are also known to disable the transcriptional repressor activity of the UNC-4 and UNC-37 proteins, it seems unlikely that the UNC-4-UNC-37 complex acts as a direct 


\section{wild type}
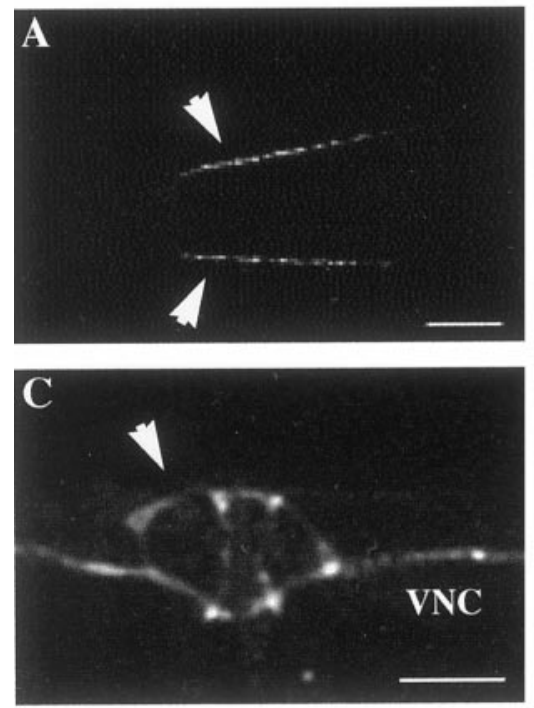

$\mathbf{E}$

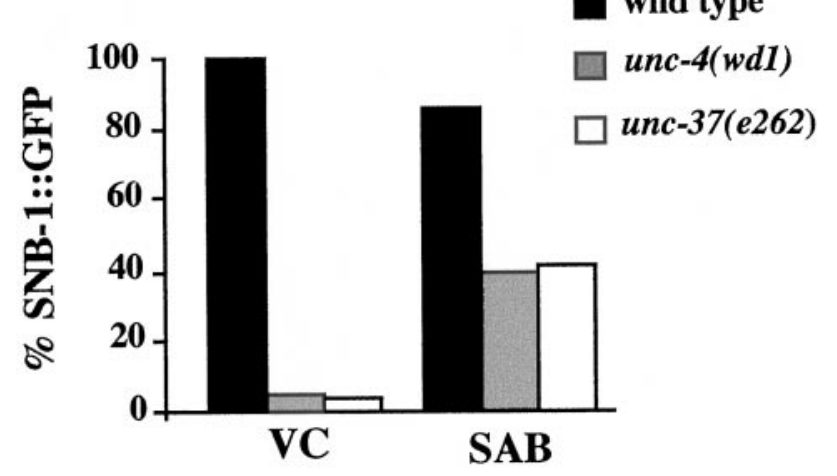

regulator of SV gene transcription. If that were the case, then SV protein levels should increase in unc-4 and unc-37 mutants as opposed to the substantial reduction of vesicular proteins that we observe in these animals. Thus, we propose that the UNC-4 and UNC-37 normally function to repress transcription of an intermediate gene (gene- $x$ ) that in turn exerts a negative effect on SV levels (Fig. 9). In this model, mutations that disable either unc-4 or unc-37 result in inappropriate expression of gene-x that then downregulates SV proteins. Although the molecular identity of the putative gene- $x$ is unknown, our results indicate that it is likely to act via a posttranscriptional mechanism.

Studies of SV biogenesis in vertebrate neurons have revealed multiple post-transcriptional levels of control. For example, in cultured hippocampal neurons, Synaptophysin expression appears to depend on the rate of mRNA translation, whereas the accumulation of Synaptotagmin, Synaptobrevin, and Synapsin is linked to increased protein half-life as these neurons develop. The rates of SV assembly and SV protein degradation may be interdependent; SV creation relies on the available pool of SV proteins, and conversely, precursor proteins that are not rapidly incorporated into an SV may be degraded (Daly and Ziff, 1997). Wide variations in SV number and quantal content among different classes of neurons argue that developmental and homeostatic control of vesicle-dependent signaling capacity is inherently important to neuronal physiology
Figure 8. GFP-tagged Synaptobrevin is downregulated in unc-4-mutant motor neurons. The unc-4 promoter was used to drive expression of SNB-1::GFP (M. L. Nonet, 1999). $A-D$, Punctate SNB-1::GFP staining is seen in $\operatorname{SAB}(A)$ and $\mathrm{VC}$ processes $(C)$ in wild-type animals but is either reduced $(B)$ or eliminated $(D)$ in these neurons in unc-37(e262) mutants (arrows). Images are compressed stacks of optical sections obtained in the confocal microscope. $E$, Histogram of SNB-1::GFP expression in VC and SAB motor neurons shows decreased GFP expression in unc-4(wd1) and unc37(e262) mutants. Two sets of VC vulval synapses (anterior vs posterior) were scored per animal. Staining of these VC varicosities was usually correlated with staining in the adjacent VC4 and VC5 somata ( $n=60$ animals). Four SAB processes were scored per animal ( $n=80$ animals). Scale bars, $10 \mu \mathrm{m}$.
(White et al., 1986; Jia et al., 1993; Merchan-Perez and Liberman, 1996). Tight regulation of SV levels could be provided by the opposing effects of both positively and negatively acting pathways. In this instance, the normal function of unc-4 and unc-37 is to inhibit the activity of a negatively acting pathway that acts, via a post-transcriptional mechanism, to decrease the levels of SV proteins and the vesicles that they comprise in specific cholinergic motor neurons.

The negative effect of the unc-4 mutation on cholinergic SVs also applies to other classes of neurotransmitter vesicles. Antibody-staining experiments have detected reduced expression of the neuropeptide FMRFamide (Li and Chalfie, 1990; Schinkmann and $\mathrm{Li}$, 1992) (C. $\mathrm{Li}$, personal communication) and the vesicular monoamine transporter in the $\mathrm{VC}$ motor neurons (Duerr et al., 1999) (Duerr, unpublished observations). These observations indicate that $u n c-4$ and $u n c-37$ may mediate a general event in the creation or maintenance of all types of neurotransmitter vesicles.

Experiments with a temperature-sensitive unc-4 mutant indicate that SV levels depend on unc-4 function during a brief period of early development but do not require unc-4 activity in the adult. This finding may mean that unc-4 and unc-37 mediate a key event during the differentiation of an affected motor neuron that then sets the steady-state level of SV proteins in the mature cell (see below). 
Table 3. UNC-17 expression in A-class motor neurons is temperature sensitive in unc-4(e2322ts) animals

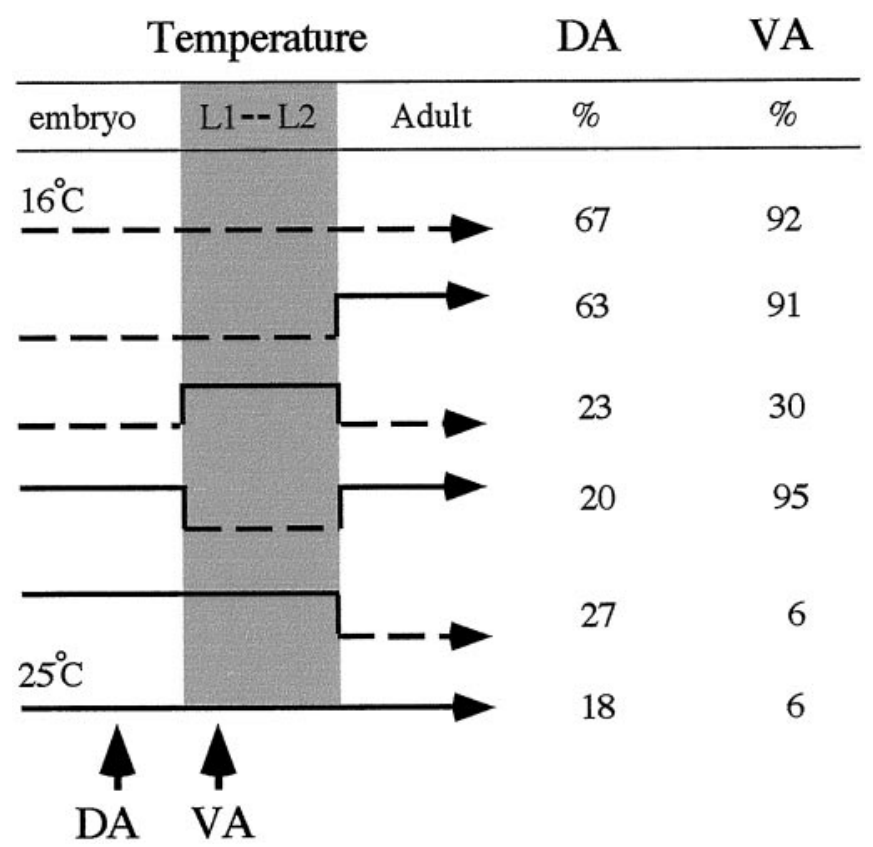

Six different temperature regimens, depicted by the horizontal lines, were applied in this experiment. A dashed line indicates growth at $16^{\circ} \mathrm{C}$, and a solid line indicates growth at $25^{\circ} \mathrm{C}$. VA $(n \geq 80)$ and DA $(n \geq 60)$ motor neurons were scored individually (as described in Fig. 2). Column labels are as follows: embryo, temperature at which the animals were grown until hatching; L1-L2, temperature at which the animals were grown until the late L2 stage; adult, temperature at which the animals were grown until the early adult stage, when they were immunostained for UNC-17 expression; and \%, percentage of DA and VA motor neurons showing wild-type levels of UNC-17 antibody staining. Arrows indicate approximate birthdates of DA and VA motor neurons. Gray background demarcates L1-L2 stages.

\section{Motor neuron dysfunction contributes to the Unc-4 movement defect}

Body wall muscle excitation during backward locomotion has been attributed to the coordinated activities of cholinergic DA and VA motor neurons and the command interneurons (AVA, AVD, and AVE) that drive them (Chalfie et al., 1985). The striking backward movement defect shown by unc-4 and unc-37 loss-of-function mutants is correlated with the loss of normal inputs to VA motor neurons. These synapses are replaced with gap junctions from a command interneuron (AVB) that usually mediates forward locomotion (White et al., 1992) (Hall, German, and Miller, unpublished observations). Recent results suggest that the simple elimination of synaptic inputs to the VAs may be insufficient to account for the total abrogation of backward movement in unc-4 mutants; genetic ablation of the "backward command interneurons" (AVA, AVD, and AVE) retards but does not block reverse locomotion (Zheng et al., 1999). Our finding that the neurotransmitter signaling capacity of VA motor neurons is also reduced in unc-4 mutants may provide an explanation for the enhanced severity of the Unc-4 backward movement defect.

\section{Does the vesicular signaling capacity of VA motor neurons specify presynaptic inputs or vice versa?}

Experiments with a temperature-sensitive unc-4 mutant indicate that both the input and output defects of VA motor neurons are caused by the loss of unc-4 activity during early larval development. VA motor neurons are generated during the first larval stage (L1) (Sulston and Horvitz, 1977). Although the adult pat-
$\mathbf{A}$

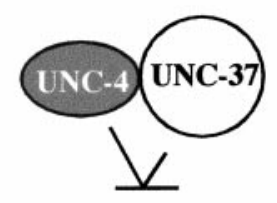

gene-X

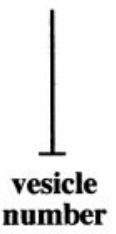

B Wild Type
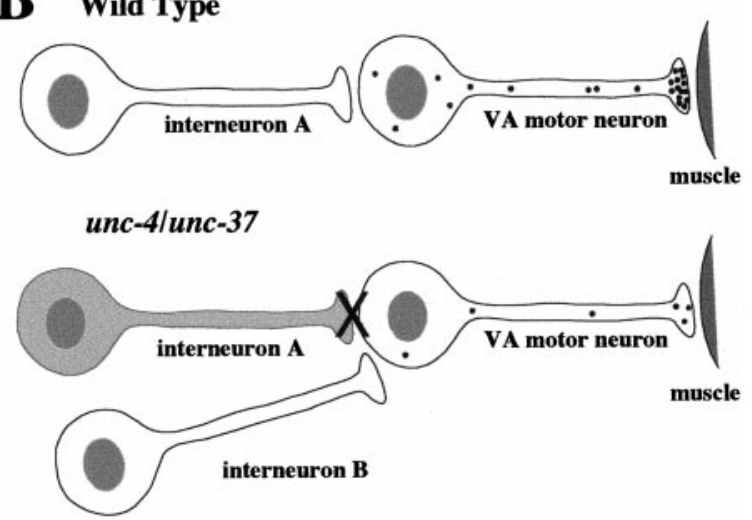

Figure 9. Model. $A$, UNC-4 and UNC-37 function together to repress an intermediate gene (gene-x) that negatively regulates vesicle number. In unc-4 or unc-37 loss-of-function mutants, gene- $x$ is derepressed, thereby leading to decreased levels of synaptic vesicles and SV proteins. $B$, In wild-type animals, VA motor neurons receive input from specific command interneurons (interneuron A). In unc-4 and unc-37 mutants, VA motor neurons exhibit a reduced number of SVs and receive input from a different set of presynaptic partners (interneuron B) (White et al., 1992) (Hall, German, and Miller, unpublished observations).

tern of presynaptic connections is established before the L1-L2 molt (J. White, personal communication), additional motor neuron inputs are probably added during subsequent larval development to accompany dramatic increases in neuronal size (Rongo and Kaplan, 1999). If unc-4 activity is effectively turned off during this critical period (L2 to mid-L3) by exposing the unc-4ts allele to a restrictive temperature, then adult animals show a strong backward movement defect (Miller et al., 1992) as well as a reduction in synaptic vesicles in the VAs. The temporal correlation of the miswiring event and the reduction in VA signaling capacity is suggestive of a causal relationship between these defects.

In one model, the change in synaptic inputs triggers the depletion of synaptic vesicles in the VAs. However, an identical mechanism could not account for the loss of synaptic vesicles in the DAs because these motor neurons are not miswired in unc-4 mutants. Perhaps the unc-4 mutation induces transient miswiring of the DAs (and SAB and VC motor neurons), and this brief loss of normal inputs is sufficient to induce the synaptic vesicle defect.

It is also possible that the opposite mechanism applies. The loss of vesicular proteins in the VA motor neurons results in an altered pattern of presynaptic inputs. This model supposes that either the vesicular proteins or the signaling activity that they provide may define presynaptic specificity. Ample evidence exists for models 
in which both the strength and selectivity of presynaptic connections can be influenced by retrograde signals from the postsynaptic partner. The mechanisms of these effects, however, are primarily unknown (Fitzsimonds and Poo, 1998). Recent experiments have shown that $N$-ethylmaleimide-sensitive factor (NSF), a cytosolic protein involved in vesicular fusion, may be involved in targeting glutamate receptors to the postsynaptic membrane (Nishimune et al., 1998; Osten et al., 1998; Song et al., 1998). In addition, the application of inhibitors of NSF activity or cleavage of the SNARE protein Synaptobrevin by microinjection or cell autonomous expression of tetanus toxin can reduce the strength of synaptic inputs to the affected neurons (Lledo et al., 1998; Baines et al., 1999). These studies indicate that SV fusion may be important for the correct localization of receptors at the postsynaptic membrane in addition to providing neurotransmitter signaling capacity at the presynaptic density. It is conceivable that a similar effect on the localization of key receptor or marker proteins in the VA postsynaptic membrane could effectively specify presynaptic inputs. This model predicts that VA motor neurons should adopt the VB pattern of synaptic inputs in mutants in which SV accumulation or activity is reduced (Jorgensen et al., 1995). This model also assumes, of course, that the loss of SV activity in other classes of motor neurons (e.g., the DAs) is not sufficient to alter presynaptic inputs.

Lastly, it is conceivable that the loss of synaptic vesicles and the rewiring of VA motor neurons are independently induced by the unc-4 mutation and have no mechanistic relationship other than the common link to $u n c-4$ activity. Perhaps the most effective way to resolve this question is to identify the $u n c-4$ target genes that mediate these events.

\section{REFERENCES}

Alfonso A, Grundahl K, Duerr JS, Han HP, Rand JB (1993) The Caenorhabditis elegans unc-17 gene: a putative vesicular acetylcholine transporter. Science 261:617-619.

Alfonso A, Grundahl K, McManus JR, Asbury JM, Rand JB (1994) Alternative splicing leads to two cholinergic proteins in Caenorhabditis elegans. J Mol Biol 241:627-630.

Baines RA, Robinson SG, Fujioka M, Jaynes JB, Bate M (1999) Postsynaptic expression of tetanus toxin light chain blocks synaptogenesis in Drosophila. Curr Biol 9:1267-1270.

Bergmann M, Lahr G, Mayerhofer A, Gratzl M (1991) Expression of synaptophysin during the prenatal development of the rat spinal cord: correlation with basic differentiation processes of neurons. Neuroscience 42:569-582

Brenner S (1974) The genetics of Caenorhabditis elegans. Genetics 77:71-94.

Calakos N, Scheller RH (1996) Synaptic vesicle biogenesis, docking, and fusion: a molecular description. Physiol Rev 76:1-29.

Chalfie M, Sulston JE, White JG, Southgate E, Thompson JN, Brenner S (1985) The neural circuit for touch sensitivity in Caenorhabditis elegans. J Neurosci 5:956-964.

Clark DV, Suleman DS, Beckenbach KA, Gilchrist EJ, Baillie DL (1995) Molecular cloning and characterization of the dpy-20 gene of Caenorhabditis elegans. Mol Gen Genet 247:367-378.

Cremona O, De Camilli P (1997) Synaptic vesicle endocytosis. Curr Opin Neurobiol 7:323-330.

Daly C, Ziff EB (1997) Post-transcriptional regulation of synaptic vesicle protein expression and the developmental control of synaptic vesicle formation. J Neurosci 17:2365-2375.

Deans ZC, Dawson SJ, Kilimann MW, Wallace D, Wilson MC, Latchman DS (1997) Differential regulation of genes encoding synaptic proteins by the Oct-2 transcription factor. Brain Res Mol Brain Res 51:1-7.

Duerr JS, Frisby DL, Gaskin J, Duke A, Asermely K, Huddleston D, Eiden LE, Rand JB (1999) The cat-1 gene of Caenorhabditis elegans encodes a vesicular monoamine transporter required for specific monoamine-dependent behaviors. J Neurosci 19:72-84.

Fitzsimonds RM, Poo MM (1998) Retrograde signaling in the development and modification of synapses. Physiol Rev 78:143-170.

Geppert M, Bolshakov VY, Siegelbaum SA, Takei K, De Camilli P, Hammer RE, Sudhof TC (1994) The role of Rab3A in neurotransmitter release. Nature 369:493-497.

Hall DH, Hedgecock ED (1991) Kinesin-related gene unc-104 is re- quired for axonal transport of synaptic vesicles in C. elegans. Cell 65:837-847.

Hosono R, Hekimi S, Kamiya Y, Sassa T, Murakami S, Nishiwaki K, Miwa J, Taketo A, Kodaira KI (1992) The unc-18 gene encodes a novel protein affecting the kinetics of acetylcholine metabolism in the nematode Caenorhabditis elegans. J Neurochem 58:1517-1525.

Jia XX, Gorczyca M, Budnik V (1993) Ultrastructure of neuromuscular junctions in Drosophila: comparison of wild type and mutants with increased excitability. J Neurobiol [Erratum (1994) 25:893-895] 24:1025-1044.

Jin Y, Jorgensen E, Hartwieg E, Horvitz HR (1999) The Caenorhabditis elegans gene unc-25 encodes glutamic acid decarboxylase and is required for synaptic transmission but not synaptic development. J Neurosci 19:539-548.

Jorgensen EM, Hartwieg E, Schuske K, Nonet ML, Jin Y, Horvitz HR (1995) Defective recycling of synaptic vesicles in synaptotagmin mutants of Caenorhabditis elegans. Nature 378:196-199.

Kao HT, Porton B, Hilfiker S, Stefani G, Pieribone VA, DeSalle R, Greengard P (1999) Molecular evolution of the synapsin gene family. J Exp Zool 285:360-377.

Li C, Chalfie M (1990) Organogenesis in C. elegans: positioning of neurons and muscles in the egg-laying system. Neuron 4:681-695.

Li L, Chin LS, Shupliakov O, Brodin L, Sihra TS, Hvalby O, Jensen V, Zheng D, McNamara JO, Greengard P, Andersen P (1995) Impairment of synaptic vesicle clustering and of synaptic transmission, and increased seizure propensity, in synapsin I-deficient mice. Proc Natl Acad Sci USA 92:9235-9239.

Lledo PM, Zhang X, Sudhof TC, Malenka RC, Nicoll RA (1998) Postsynaptic membrane fusion and long-term potentiation. Science 279:399-403.

Lloyd TE, Verstreken P, Ostrin EJ, Phillippi A, Lichtarge O, Bellen HJ (2000) A genome-wide search for synaptic vesicle cycle proteins in Drosophila. Neuron 26:45-50.

Lou X, Bixby JL (1993) Coordinate and noncoordinate regulation of synaptic vesicle protein genes during embryonic development. Dev Biol 159:327-337.

McIntire SL, Jorgensen E, Kaplan J, Horvitz HR (1993) The GABAergic nervous system of Caenorhabditis elegans. Nature 364:337-341.

Mello C, Fire A (1995) DNA transformation. Methods Cell Biol 48:451-482.

Melloni Jr RH, Apostolides PJ, Hamos JE, DeGennaro LJ (1994) Dynamics of synapsin I gene expression during the establishment and restoration of functional synapses in the rat hippocampus. Neuroscience 58:683-703.

Merchan-Perez A, Liberman MC (1996) Ultrastructural differences among afferent synapses on cochlear hair cells: correlations with spontaneous discharge rate. J Comp Neurol 371:208-221.

Miller DM, Shen MM, Shamu CE, Burglin TR, Ruvkun G, Dubois ML, Ghee M, Wilson L (1992) C. elegans unc-4 gene encodes a homeodomain protein that determines the pattern of synaptic input to specific motor neurons. Nature 355:841-845.

Miller DM, Desai N, Hardin D, Piston DW, Patterson GH, Fleenor J, Xu SQ, Fire A (1999) A two-color GFP expression system for C. elegans. Biotechniques 26:914-921.

Miller III DM, Niemeyer CJ (1995) Expression of the unc-4 homeoprotein in Caenorhabditis elegans motor neurons specifies presynaptic input. Development 121:2877-2866.

Miller III DM, Niemeyer CJ, Chitkara P (1993) Dominant unc-37 mutations suppress the movement defect of a homeodomain mutation in unc-4, a neural specificity gene in Caenorhabditis elegans. Genetics 135:741-753.

Miller KG, Alfonso A, Nguyen M, Crowell JA, Johnson CD, Rand JB (1996) A genetic selection for Caenorhabditis elegans synaptic transmission mutants. Proc Natl Acad Sci USA 93:12593-12598.

Nishimune A, Isaac JT, Molnar E, Noel J, Nash SR, Tagaya M, Collingridge GL, Nakanishi S, Henley JM (1998) NSF binding to GluR2 regulates synaptic transmission. Neuron 21:87-97.

Nonet M (1999) Studying mutants that affect neurotransmitter release in C. elegans. In: Neurotransmitter release (Bellen HJ, ed), pp 265-303. New York: Oxford UP.

Nonet ML (1999) Visualization of synaptic specializations in live $C$. elegans with synaptic vesicle protein-GFP fusions. J Neurosci Methods $89 \cdot 33-40$.

Nonet ML, Grundahl K, Meyer BJ, Rand JB (1993) Synaptic function is impaired but not eliminated in C. elegans mutants lacking synaptotagmin. Cell 73:1291-1305.

Nonet ML, Staunton JE, Kilgard MP, Fergestad T, Hartwieg E, Horvitz HR, Jorgensen EM, Meyer BJ (1997) Caenorhabditis elegans rab-3 mutant synapses exhibit impaired function and are partially depleted of vesicles. J Neurosci 17:8061-8073.

Nonet ML, Saifee O, Zhao H, Rand JB, Wei L (1998) Synaptic transmission deficits in Caenorhabditis elegans synaptobrevin mutants. J Neurosci 18:70-80.

Nonet ML, Holgado AM, Brewer F, Serpe CJ, Norbeck BA, Holleran J, Wei L, Hartwieg E, Jorgensen EM, Alfonso A (1999) UNC-11, a 
Caenorhabditis elegans AP180 homologue, regulates the size and protein composition of synaptic vesicles. Mol Biol Cell 10:2343-2360.

Ogawa H, Harada S, Sassa T, Yamamoto H, Hosono R (1998) Functional properties of the unc-64 gene encoding a Caenorhabditis elegans syntaxin. J Biol Chem 273:2192-2198.

Osten P, Srivastava S, Inman GJ, Vilim FS, Khatri L, Lee LM, States BA, Einheber S, Milner TA, Hanson PI, Ziff EB (1998) The AMPA receptor GluR2 C terminus can mediate a reversible, ATP-dependent interaction with NSF and alpha- and beta-SNAPs. Neuron 21:99-110.

Petersohn D, Schoch S, Brinkmann DR, Thiel G (1995) The human synapsin II gene promoter. Possible role for the transcription factor zif268/egr-1, polyoma enhancer activator 3, and AP2. J Biol Chem 270:24361-24369.

Pflugrad A, Meir JY-J, Barnes TM, Miller III DM (1997) The Groucholike transcription factor UNC-37 functions with the neural specificity gene unc-4 to govern motor neuron identity in C. elegans. Development 124:1699-1709.

Richmond JE, Davis WS, Jorgensen EM (1999) UNC-13 is required for synaptic vesicle fusion in C. elegans. Nat Neurosci 2:959-964.

Rongo C, Kaplan JM (1999) CaMKII regulates the density of central glutamatergic synapses in vivo. Nature 402:195-199.

Rosahl TW, Spillane D, Missler M, Herz J, Selig DK, Wolff JR, Hammer RE, Malenka RC, Sudhof TC (1995) Essential functions of synapsins I and II in synaptic vesicle regulation. Nature 375:488-493.

Rothman JE (1994) Mechanisms of intracellular protein transport. Nature 372:55-63.

Saifee O, Wei L, Nonet ML (1998) The Caenorhabditis elegans unc-64 locus encodes a syntaxin that interacts genetically with synaptobrevin. Mol Biol Cell 9:1235-1252.

Schinkmann K, Li C (1992) Localization of FMRFamide-like peptides in Caenorhabditis elegans. J Comp Neurol 316:251-260.

Smith MD, Dawson SJ, Latchman DS (1997) The Brn-3a transcription factor induces neuronal process outgrowth and the coordinate expression of genes encoding synaptic proteins. Mol Cell Biol 17:345-354.

Song I, Kamboj S, Xia J, Dong H, Liao D, Huganir RL (1998) Interaction of the $N$-ethylmaleimide-sensitive factor with AMPA receptors. Neuron 21:393-400.
Sulston J, Hodgkin J (1988) Methods. In: The nematode Caenorhabditis elegans (Wood WB, ed), pp 587-606. Cold Spring Harbor, NY: Cold Spring Harbor Laboratory.

Sulston JE, Horvitz HR (1977) Post-embryonic cell lineages of the nematode, Caenorhabditis elegans. Dev Biol 56:110-156.

Sulston JE, Schierenberg E, White JG, Thomson JN (1983) The embryonic cell lineage of the nematode Caenorhabditis elegans. Dev Biol 100:64-119.

Takei Y, Harada A, Takeda S, Kobayashi K, Terada S, Noda T, Takahashi T, Hirokawa N (1995) Synapsin I deficiency results in the structural change in the presynaptic terminals in the murine nervous system. J Cell Biol 131:1789-1800.

Trent C, Tsung N, Horvitz H (1983) Egg-laying defective mutants of the nematode Caenorhabditis elegans. Genetics 104:619-647.

Waggoner LE, Zhou GT, Schafer RW, Schafer WR (1998) Control of alternative behavioral states by serotonin in Caenorhabditis elegans. Neuron 21:203-214.

White JG, Southgate E, Thomson JN, Brenner S (1976) Structure of the ventral nerve cord of Caenorhabditis elegans. Philos Trans R Soc Lond [Biol] 275:327-348.

White JG, Southgate E, Thomson JN, Brenner S (1986) The structure of the nervous system of the nematode Caenorhabditis elegans. Philos Trans R Soc Lond [Biol] 314:1-340.

White JG, Southgate E, Thomson JN (1992) Mutations in the Caenorhabditis elegans unc-4 gene alter the synaptic input to ventral cord motor neurons. Nature 355:838-841.

Winnier AR, Meir JY, Ross JM, Tavernarakis N, Driscoll M, Ishihara T, Katsura I, Miller III DM (1999) UNC-4/UNC-37-dependent repression of motor neuron-specific genes controls synaptic choice in Caenorhabditis elegans. Genes Dev 13:2774-2786.

Zhao H, Nonet ML (2000) A retrograde signal is involved in activitydependent remodeling at a $C$. elegans neuromuscular junction. Development 127:1253-1266.

Zheng Y, Brockie PJ, Mellem JE, Madsen DM, Maricq AV (1999) Neuronal control of locomotion in $C$. elegans is modified by a dominant mutation in the GLR-1 ionotropic glutamate receptor. Neuron 24:347361. 